\title{
HÁGALO USTED MISMO: ARQUITECTURA, HIGIENE Y MORAL
}

\section{Popularización del saber técnico y medicalización del espacio privado en los procesos civilizatorios del siglo XX. (Segunda parte)}

\author{
Alirio Rangel Wilches*
}

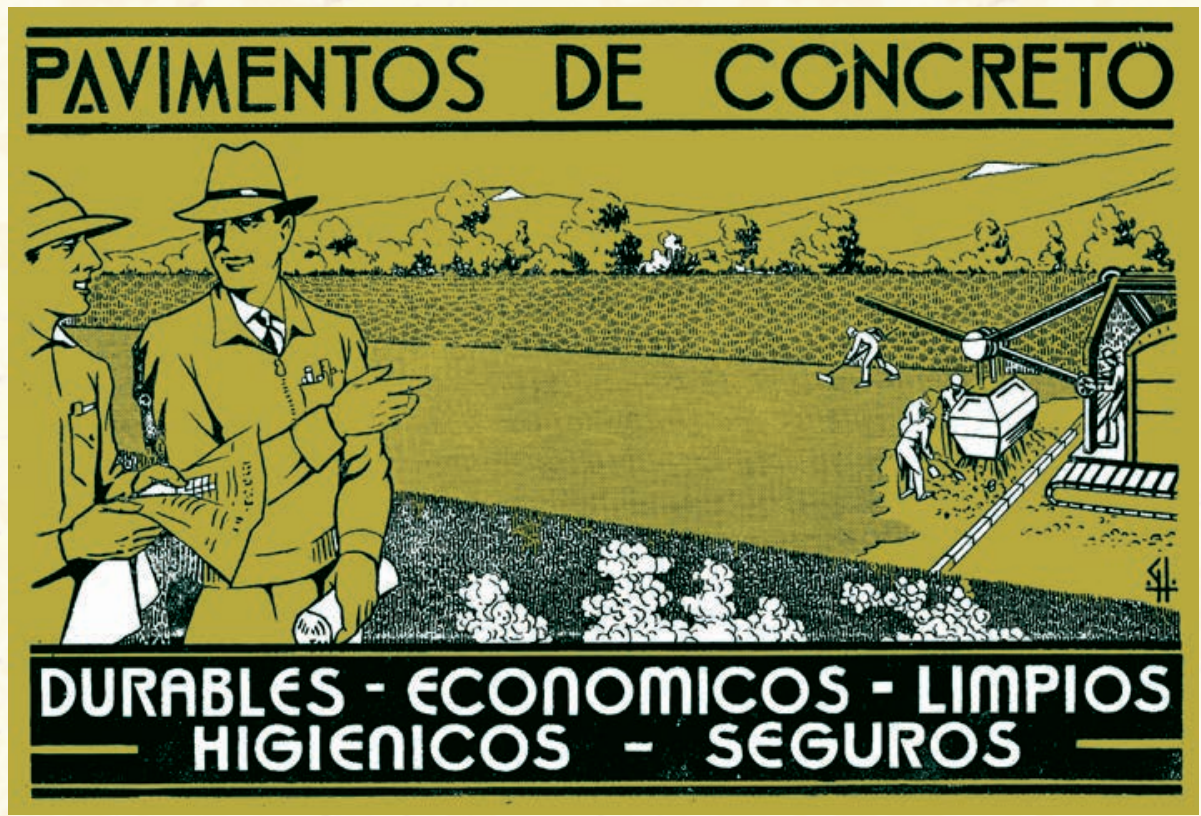

El documento que publicamos retoma algunas ideas del documento presentado para optar al título del Máster oficial europeo en Historia y Teoría de la Arquitectura de la UPC, bajo la dirección de la historiadora del arte, profesora Carmen Rodríguez Pedret. Este trabajo fue continuado y actualizado en el proyecto de investigación aprobado para el Doctorado en Teoría e Historia de la Arquitectura, UPC, Barcelona, 2008, bajo la dirección de la arquitecta Marta Llorente. El autor agradece a las profesoras Carmen Rodríguez y Marta Llorente por sus aportes, orientaciones y especial dedicación.

Revista M. Enero-Junio de 2009. Volumen 6 Número I, pp. 66-96.

\section{RESUMEN}

Este texto señala las modificaciones que introducen las literaturas técnicas al convertirse en mediaciones culturales, movidas en su interés por facilitar las transferencias tecnológicas en contextos periféricos; dicha tendencia se circunscribirá en un arco temporal que se inicia con las láminas didácticas de L'Encyclopédie en el siglo XVIII y que tendrá su punto álgido con la masificación de los logros técnicos en los siglos $\mathrm{XIX}$ y $\mathrm{XX}$ a través de publicaciones divulgadoras o de extensión. Se considerará aquí que este proceso es paralelo a la consolidación, dentro del Estado moderno, de la cultura técnica como un nuevo grupo de acción frente a la tradicional tensión entre la alta cultura y la cultura de masas.

En una entrega anterior' se analizaban las modificaciones iconográficas de los modos de representación propios de la cultura técnica en la primera mitad del siglo $X X$; ahora se asociarán estos cambios de la imagen técnica con ciclos más amplios y de mayor duración: de un lado, las alteraciones en los procesos creativos de los gremios constructivos y en los modos de transmisión del saber técnico; de otro lado, la aceptación creciente de la higiene y la masificación de la vida acomodada por parte de los usuarios de las nuevas tecnologías del confort en los confines del espacio doméstico.

\section{PALABRAS CLAVE}

Aculturación, instrucciones gráficas, mediaciones culturales, literaturas técnicas, tecnologías del confort, medicalización del espacio privado. 


\section{DO IT BY YOURSELF: ARCHITECTURE, HYGIENE AND MORAL VALUES}

\section{Popularization of technical knowledge and medicalization of the private space in the process of civilization of the twentieth century.(Part II)}

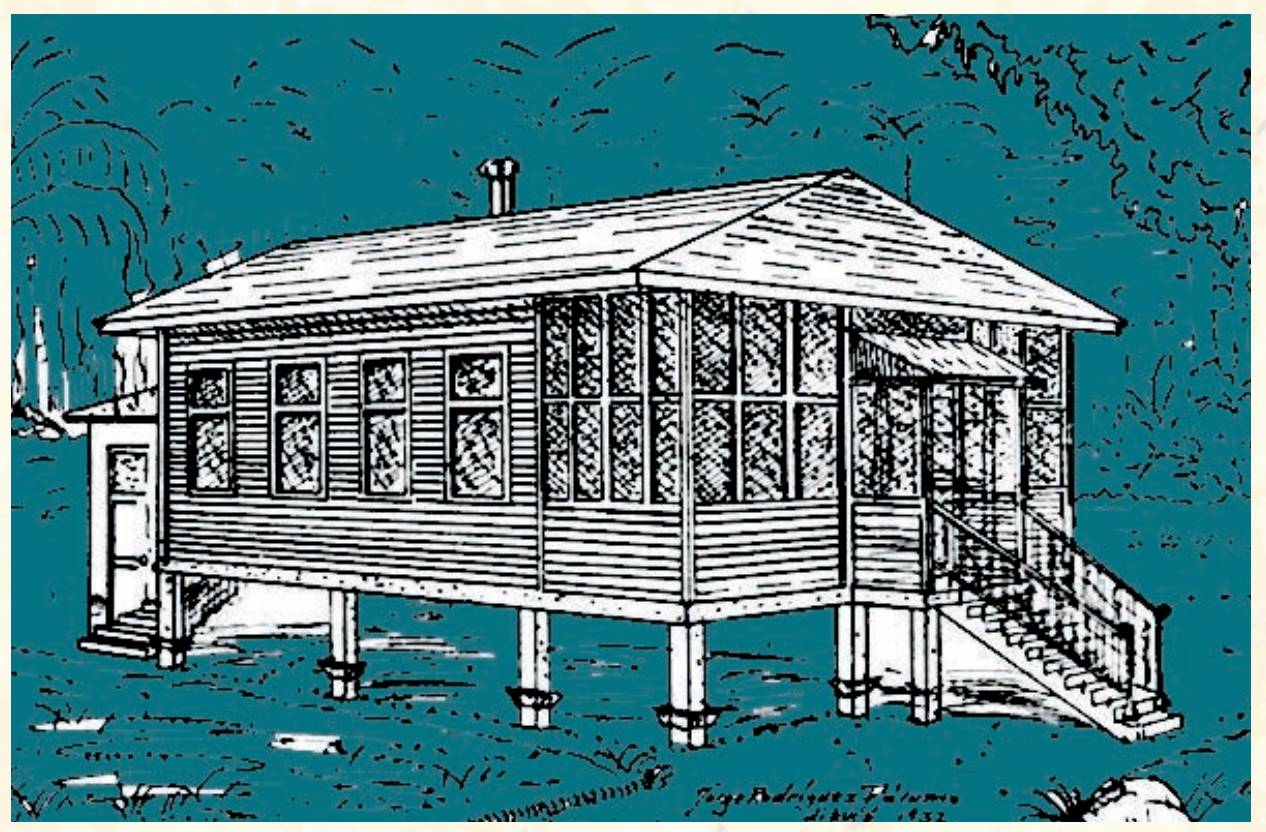

\section{ABSTRACT}

This text refers to the changes that introduce the technical literatures when they become cultural mediations, boosted in their interest to facilitate technology transfers in peripheral contexts; such trend will go along in a time span that begins with flashcards in L'Encyclopédie in the eighteenth century and which will reach its highest point with the massification of the technical achievements in the nineteenth and twentieth centuries through disclosed or extension publications. Be considered here that this process is parallel to the consolidation of the technical culture as a new action group opposed to the traditional tension between high culture and mass culture within the modern State.

In a previous installment ${ }^{2}$ the iconographic changes of the ways of representation proper of the technical culture in the first half of the $X X$ century were analized. Now, these changes will be associated to the technical image with broader and longer-lasting cycles: On one side, the alterations in the creative processes of the construction unions and in the ways of transmission of technical knowledge, on the other hand, the growing acceptance of hygiene and life massification settled by the users of the new technologies of comfort within the confines of the domestic space.

\section{KEY WORDS}

Acculturation, graphic instructions, cultural mediation, technical literature, technology of comfort, medicalization of private space.
2 M. Magazine January-June 2009.Volume 6 Issue I, pp. 66-96. 


\section{Higienización de la vida íntima}

La medicalización del espacio privado y su implementación en estratos sociales con un énfasis cada vez menos exclusivista introduce un giro en el proceso de divulgación del saber técnico al despertar el interés de los colectivos especializados por las transferencias tecnológicas para los usuarios legos. Esta inflexión implica despojar a la imagen técnica de su especificidad característica, enfatizando en su aspecto comparativo, explícito y didáctico. En otros términos: a partir del siglo XVIII se esboza una dinámica de la reproducción masiva de la imagen técnica -despojada de la complejidad selectiva que la caracterizabadinámica que constituye una parte fundamental del proceso civilizatorio, definida por la tecnificación de la vida cotidiana en la transición hacia la modernidad en las conductas relativas a los lugares del habitar.

Se intentará vincular el concepto de los procesos civilizatorios de control social de Norbert Elias con la redifinición de la imagen técnica y los cambios en las modalidades de transmisión del saber propios de las sociedades con tendencia a la industrialización o, al menos, a una mayor división del trabajo, pero que aún cuentan con brechas en el acceso al control de la técnica.

Previamente se planteaba una lectura iconológica de aquellas publicaciones de importancia secundaria para la historiografía de la arquitectura moderna, agrupadas bajo el amplio espectro de las instrucciones gráficas: aquellos manuales, cartillas, revistas y otros medios impresos de divulgación que vinculan, dentro del medio técnico de la construcción arquitectónica, temas exógenos como las nuevas prácticas culturales que alteran las costumbres ancestrales. Esta nueva tendencia postula una vida "sana" dentro del espacio privado desde una perspectiva conductista y hegemónica.

Estas prácticas se originan en el interés por aumentar la calidad de vida aduciendo discursos afines a la ciencia, a través de los postulados médicos del higienismo y de prejuicios empírico-conductistas asociados con la moral laica; todos ellos acogidos dentro del contexto del Estado moderno occidental, que en el siglo $X X$ asume las premisas de la industrialización y la economía del capital, consciente de que aún no se han subsanado las profundas diferencias entre los diversos colectivos que integran la sociedad. Tales diferencias se remiten no solamente al dominio del poder político y económico, sino que también contemplan el acceso al saber y al control de la tecnología. Es aquí donde aparecen las transferencias tecnológicas que facilitarían esa transición hacia una sociedad moderna, modificando progresivamente el componente técnico-constructivo de las edificaciones, aproximándolo a la vez con los ritmos de aceptación de los dispositivos y aditamentos que definen una vida "moderna" en su interior. De esta manera, tanto el componente arquitectónico, como los aditamentos de las tecnologías del confort que se despliegan en los espacios contenidos, modificarían favorablemente los habitus de sus usuarios-ocupantes.

3 Muchos de ellos se originarán en el siglo $\mathrm{XIX}$, independientemente de las manifestaciones formales recargadas $y$ las tendencias estilísticas eclécticas que adoptarán los gestores del confort en la sociedad victoriana.

El punto de interés radica en cómo algunos discursos exógenos que preocupan a la modernidad arquitectónica del siglo $\mathrm{XX}^{3}$-el higienismo y la taylorización, tanto en los modos de producción como en los modos de consumo y los modos de habitar- se masifican a través de medios impresos de menor visibilidad histórica (en comparación con las revistas, manifiestos, propaganda y otros recursos vanguardistas de primera línea). A diferencia de los textos panfletarios de los vanguardistas y de su contraparte reaccionaria en cabeza de los tradicionalistas, estos materiales divulgativos conjugan, en cierta medida, los intereses de las vanguardias artístico-arquitectónicas con las tradiciones constructivas, que en otros ámbitos serían irreconciliables. La consuetudinaria disputa entre vanguardia y tradición "bajará la guardia" en aras de la medicalización de la vida doméstica; así aparecen 
estos recursos de extensión del saber técnico como nuevas mediaciones culturales en las dinámicas de popularización de la vida moderna.

Fig. I. Con el uso del diagrama como mediación cultural por la didáctica de la medicina, la imagen técnica pretenderá "hacer visibles" procesos ocultos u aparentemente ininteligibles para las masas populares (especialmente aquellos relacionados con las enfermedades contagiosas y endémicas

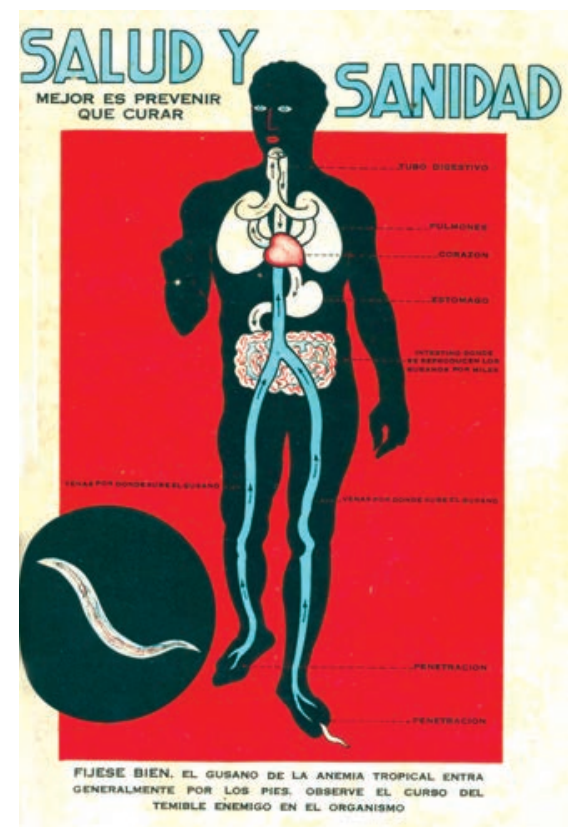

Fuente: Revista Salud y Sanidad N50. Ministerio de Salud, Colombia, junio de 1936.

La medicalización del espacio doméstico es un proceso externo a la tradición constructiva: introduce temas específicos de la medicina preventiva como el control de plagas y enfermedades endémicas a partir de protocolos y recursos técnicos de baja complejidad, involucrando los dispositivos materiales de la vida cotidiana: los lugares de socialización familiar (el estar o salón), los afines a las prácticas higienistas (el baño y la cocina) y los recintos de la intimidad (las habitaciones, el vestier), se pondrán al día con los últimos gadgets.

Fig. 2. En un proceso similar al empleado por la medicina preventiva, el diagrama en las tecnologías del confort ilustrará los medios para actualizar las técnicas constructivas tradicionales con recursos de la higiene, igualmente aplicados por las vanguardias arquitectónicas.

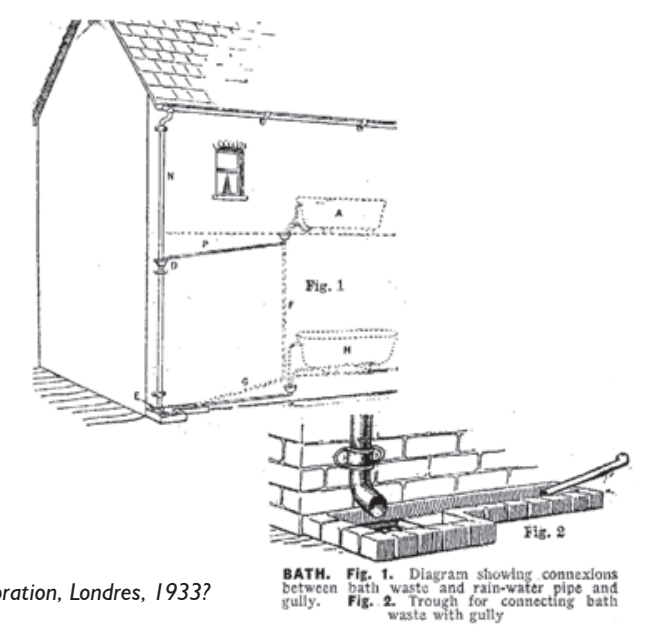


Esta medicalización también incorpora discursos de las nuevas ciencias sociales como la psicología y la antropología, relativos a la catalogación y tratamiento de las enfermedades mentales y de aquellos prejuicios que catalogan dentro de las "anomalías" a ciertos comportamientos y hábitos tradicionales, especialmente aquellos que se reflejan y espacializan en la vida privada: el dominio de la promiscuidad, el control de la natalidad, las relaciones padres-hijos $y$, en general, el dominio de las pulsiones al interior mismo de la casa; todo ello a través de dispositivos arquitectónicos con sus complementos del mobiliario y del diseño aplicado.

Fig. 3 En las periferias se implementan recursos característicos de las tecnologías de baja complejidad para combatir las enfermedades tropicales desde sus vectores de propagación.

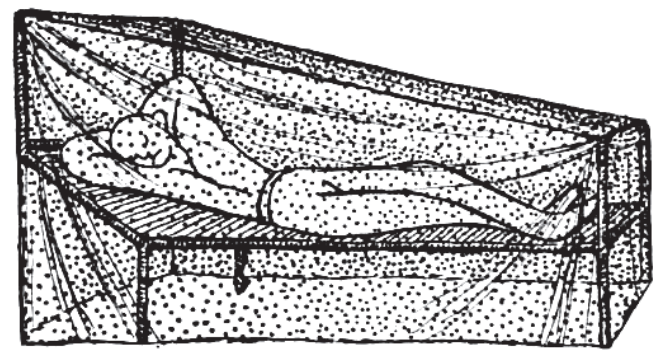

Cama con mosquitero.

Fuente: Revista Salud y Sanidad N 40-4I. Ministerio de Salud, Colombia, abril-mayo de 1935.

No es una tendencia propia del siglo $X X$, responde a las preocupaciones por la salud asociadas con los ámbitos habitacionales, formuladas en el siglo XVIII y adoptadas como políticas generales por la élite de la sociedad victoriana del siglo XIX. La particularidad del siglo XX radica en asociar los logros del taylorismo, propios de los ambientes fabriles de la segunda mitad del siglo XIX, con su puesta en práctica y mecanización a partir de la línea o cadena de montaje del fordismo. Otra diferencia en relación con momentos anteriores radica en la credibilidad que genera la cultura técnica: en su posicionamiento social, en la capacidad de modificar favorablemente los hábitos colectivos en los lugares de convivencia y los hábitos individuales por sus intervenciones materiales (en el espacio arquitectónico, en los aditamentos que lo pueblan); pero también por el giro que adquiere la imagen técnica fuera de los gremios que la producen y consumen: un modo de representación que hace aparentemente más asequibles discursos complejos para los estratos populares.

¿Cómo controlar las malas prácticas del espacio privado: prácticas que se extienden desde lo físico y lo fisiológico hasta lo moral y lo psicológico?, ¿Cómo "explicar" a un usuario lego procesos abstractos, "invisibles" $y$, especialmente, anti-naturales?

Fig. 4 De la misma manera que el cuerpo se protege contra los factores que amenazan su integridad, la casa se aísla del entorno -aún en los lugares más recónditos en donde la naturaleza tiene una fuerte presencia.

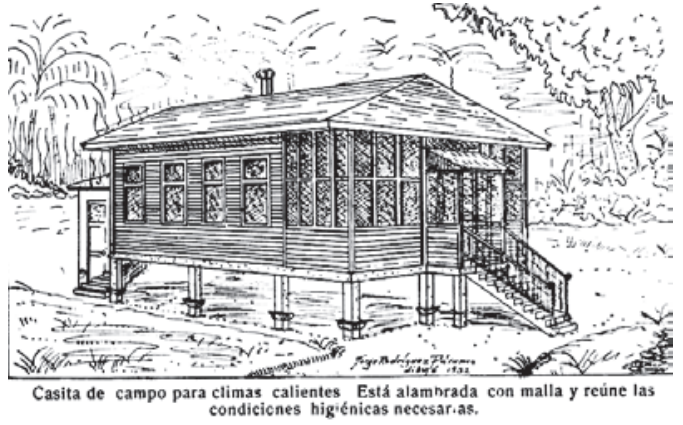

Fuente: Revista Salud y Sanidad N ㅇ 38-39. Ministerio de Salud, Colombia, febrero-marzo de 1935 


\section{Aparición y consolidación de la cultura técnica}

La tendencia por llevar la racionalización y mecanización del mundo industrial a la cotidianidad responde a una larga duración que involucra cambios estructurales en las mentalidades de las sociedades occidentalizadas. Se remite no solamente a la disputa entre las vanguardias artísticas del siglo XX y la actitud contestataria de algunas tradiciones decorativas, constructivas - defensoras de los resistentes modos de vida- sino que también proviene de más atrás: al desdibujarse la vieja tensión entre alta y baja culturas en el siglo XVIII por la aparición de una cultura técnica que reagrupa y profesionaliza los antiguos gremios de oficios, con sus efectos asociados. Sus secuelas podrían señalarse en los nuevos esquemas pedagógicos de la formación politécnica, la puesta en evidencia de los secretos de los oficios medievales, el papel preponderante del libro como soporte material y de las literaturas técnicas como estrategias en la transmisión del saber -que ya no depende de la relación directa maestro-aprendiz ni de la experiencia formativa acumulada en el taller medieval; finalmente, y como consecuencia de los anteriores, la resignificación de la imagen técnica que ya operaba en pleno desarrollo, pero que ahora tendrá varias lecturas y diferentes consumidores.

A la vez que comienza a cuestionarse el esquema formativo de la tradición de Beaux Arts, algunas relaciones dentro del circuito creativo no desaparecen; incluso perduran con las vanguardias artísticas del siglo $\mathrm{XX}$, pero no sin ser alterados y sometidos a crítica: la relación del mecenazgo entre aritsta y élite, la obra de arte o el objeto arquitectónico de carácter único e irrepetible, la teoría del genio creador y el aspecto casí "genético" del talento creativo. En las sociedades con tendencia a una fuerte división del trabajo se recomponen los estamentos sociales, potenciando y segmentando lo que anteriormente y de manera genérica se conocía como clases populares: las glebas de origen campesino que mantienen su mentalidad aldeana dentro de los espacios urbanos, las corporaciones artesanales en crisis, la incipiente clase obrera y los nuevos gremios profesionalizados.

La recomposición de los órdenes sociales existentes y la aparición de nuevos actores plantea una preocupación esencial para la historiografía del desarrollo tecnológico: la incorporación de los logros técnicos en los sectores populares como parte de la tensión productiva entre centro y periferias. Esta pugna entre un "centro" de la cultura técnica en donde se postulan las principales innovaciones y una periferia que se le resiste, pero que no necesariamente está desinteresada por adquirir parte de los logros de esa "alta cultura técnica", podría asociarse rápidamente con la relación entre el Primer y el Tercer Mundo; pero esta situación se da también al interior de las naciones más industrializadas en la medida en que siguen existiendo en ellas bolsas de resistencia (tanto por motivos productivos-económicos, como por actitudes de rechazo cultural).

¿Cómo relacionar dos posturas frente a la Historia de la Técnica: una historia per se de los logros técnicos y una historia de las dinámicas socials, en la que el desarrollo tecnológico es un componente de las tendencias civilizatorias? La primera, una historia de la mecanización de las sociedades modernas basada en la noción del progreso continuo y en el esquema de una alta cultura técnica que produce innovaciones, complementada por una élite social en sintonía que las incorpora con relativa facilidad; la segunda, una historia sociológica de la incorporación fluctuante de los logros técnicos en función de los cambios en las mentalidades y en las diferentes actitudes que puede generar la aparición de un invento. De un lado, aquella delimitada en el periodo que se inicia con la primera Revolución Industrial y que evoluciona "ininterrumpidamente" hasta lo contemporáneo; de otro lado, las duraciones más largas que involucran cambios en las estructuras sociales, en las mentalidades y en la respuesta de los usuarios frente a la aparición de dichas creaciones: identifica también la respuesta más lenta de algunos colectivos técnicos (aquellos 
relacionados con las tradiciones constructivas de la arquitectura y de las infraestructuras asociadas con la ingeniería civil y los equipamientos urbanos) frente a una élite más abierta y vanguardista.

¿Cómo relacionar los cambios mucho más lentos en el desarrollo de las técnicas edificatorias frente a los movimientos más rápidos de las tecnologías del confort y la vertiginosidad de las propuestas del arte, la decoración y la moda? Asimismo: ¿Cómo construir una historia de la técnica que no sea exclusivamente un recuento de la aparición de los inventos, aislados de las prácticas culturales que los incorporan y masifican?

Fig. 5 En una publicación higienista de iniciativa estatal se combina el diagrama y la viñeta para ilustrar el contexto y el ciclo de la enfermedad.

Gráfico que muestra cómo se transmiten las enfermedades de la suciedad o infecciones gastro-intestinales.

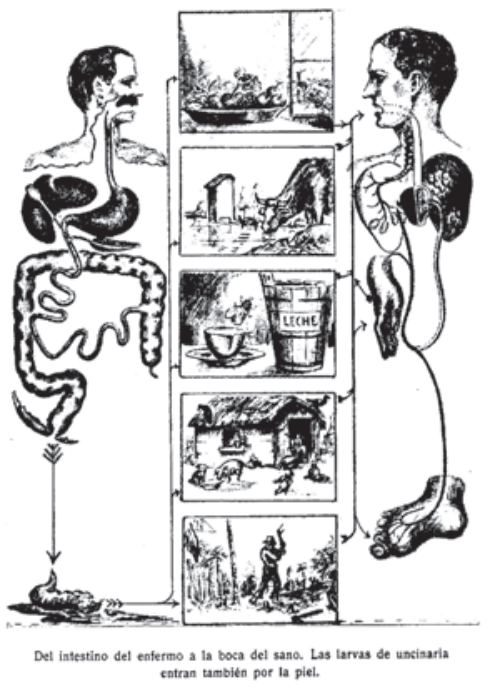

Fuente: Revista Salud y Sanidad N ${ }^{\circ} 25-26$. Ministerio de Salud, Colombia, enero-febrero de 1935.

\begin{abstract}
Fig. 6 El énfasis conductista prefiere la viñeta con su complemento de textos cortos a manera de estrofas, de fácil recordación. Además de conductas higieniénicas, buscará también el control de las relaciones sociales.
\end{abstract}

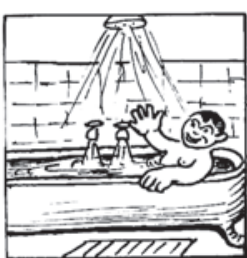

Es preciso y necesario tomar un baño a diario.

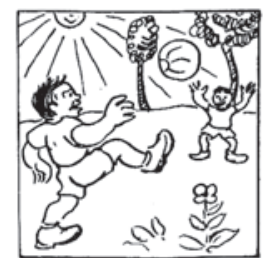

Tanto como la comida, dan el sol y el aire vida.

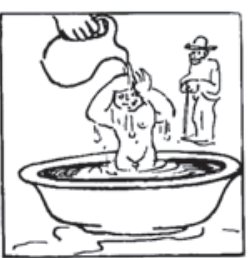

Si no tuvieses bañera te bañas de esta manera.

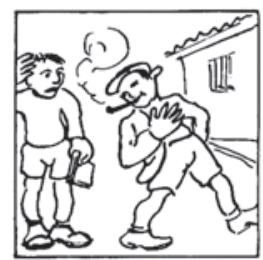

Aunque a otros veas fumar, no los debes imitar.
Fuente: Revista Salud y Sanidad $N^{\circ} 42$. Ministerio de Salud, Colombia, septiembre del935.

\section{Los procesos civilizatorios y sus afectaciones en los gremios asociados con la construcción arquitectónica}

El sociólogo judeo-alemán Norbert Elias explora en varias de sus obras aquellos procesos civilizatorios de control social que han caracterizado el devenir histórico de la sociedad occidental. Elias indaga el origen del Estado moderno a partir de las diferentes transiciones históricas: inicialmente de las sociedades guerreras del mundo antiguo a las sociedades cortesanas medievales -regentadas aún por el uso explícito de la violencia física, pero esbozando los primeros protocolos de conducta que buscan encausar la agresividad; luego siguen las cortes aristocráticas renacentistas con protocolos y códigos cada vez más refinados, en donde se proscribe el uso directo y generalizado de la fuerza, con excepción de la potestad estatal.

Elias propone que a partir del momento en que el Estado adquiere su configuración moderna, se reserva el privilegio del empleo exclusivo de la violencia con efectos punitivos para contener el orden social. Pero esta transformación no se hará visible 
exclusivamente en las modificaciones político-administrativas de los estados europeos, sino que también se traducirá en la regimentación de la vida social, en nuevos modos de comportamiento tanto en la esfera pública como en la privada. Esta disciplina punitiva se hará más visible, especialmente en lo público, a través de las tecnologías del castigo (una delimitación y refinamiento de los conceptos del placer y displacer); pero también se aplicará, en términos de Michel Foucault, una disciplina preventiva dirigida al control de los ilegalismos menores (particularmente eficaz en lo que Elias denomina como mecanismos de autocontrol de los individuos). Tal anticipación de las infracciones y las anomalías adquiere un aspecto menos amenzante; es aquí donde opera la imagen técnica a la manera de una estrategia de persuación y encauzamiento de las conductas que se consideran socialmente improcedentes.

Siguiendo con la propuesta de Elias, hay tres instancias de ejercicio de estos procesos civilizatorios: por una parte el desarrollo tecnológico como medio de control de los procesos naturales no humanos; de otro lado la organización social para guiar las relaciones interpersonales y, finalmente, el proceso civilizatorio propiamente dicho como medio de autocontrol de los individuos. Los frentes de control de aquel Estado moderno incipiente se desarrollarán en el dominio de la naturaleza ${ }^{4}$, de la sociedad en su conjunto y de cada individuo, aún en sus ámbitos más íntimos. Este proceso se esboza con la transición de la sociedad medieval a los primeras ciudades-estado $y$, posteriormente, con los radicales cambios políticos y económicos relativos a la Revolución Francesa (con la postulación de los derechos sociales) y la primera Revolución Industrial (con los derechos económicos).

El análisis de Elias relaciona códigos morales y normas de conducta con su espacialización, particularmente en los entornos urbanos; es aquí donde la arquitectura y los dispositivos del confort doméstico juegan un papel crucial. Son de particular interés las manifestaciones de los nuevos colectivos en esas relaciones interpersonales, especialmente a partir de las sociedades modernas industrializadas: es el momento de la gestación y posicionamiento de esta cultura técnica, paralela pero a la vez diferenciada de las clases obreras (la figura del técnico no se asociará completamente con los estamentos populares, caso que sí ocurría con los gremios artesanales en la Edad Media).

Se hace necesario extender la indagación de Norbert Elias en aquel intervalo en donde el Estado moderno ya se ha instaurado en el siglo $X X$ como una inclinación globalizante; sería pertinente profundizar en las consecuencias de la entrada de la imagen técnica como parte de un esfuerzo más amplio de la didáctica del saber técnico en el campo de la conducción de las relaciones interpersonales y del autocontrol de los individuos.

Las naciones occidentalizadas en el periodo de entreguerras, aún con perfiles ideológicos antagónicos, buscarán el mejoramiento de las condiciones vitales de las clases populares tanto desde la figura del Estado paternalista como desde la iniciativa de las sociedades filantrópicas, de los propios gremios técnicos e inclusive de los particulares con intereses moralistas. Esta implementación de la calidad de vida no depende exclusivamente de los logros tecnológicos (aquellos que se materializan desde las infraestructuras urbanas hasta las tecnologías del confort propias del espacio privado), sino que también implica cambios de actitud en los comportamientos grupales e individuales. ¿Si en el siglo $X X$ se perfila la medicalización del espacio privado, cuál es la respuesta de las profesiones asociadas con la gestión del confort ante las conductas que deben masificarse?
4 El trasfondo general del estudio de Elías es el dominio de la Naturaleza por los colectivos humanos, pero no solamente a partir de los mecanismos de control de lo orgánico e inorgánico externos al ser humano (Elías los denomina procesos naturales no humanos), sino también en las relaciones orgánicas de las sociedades: las relaciones interpersonales, por una parte, y el autocontrol o dominio de las pulsiones (aquella faceta que representa la animalidad humana) 
Fig. 7 Paradójicamente en los albores de los procesos civilizatorios las técnicas edificatorias son las primeras en adoptar principios de modulación y prefabricación, pero serán las más resistentes a los cambios propuestos por el régimen moderno de la vida sana.

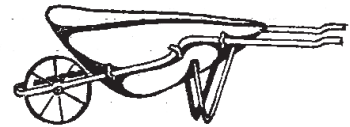

IARRETILLA

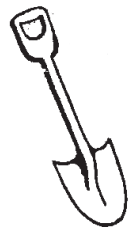

PALA

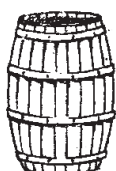

BARRIL

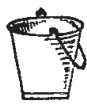

BALDE

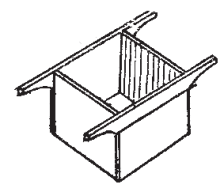

MEDIDA

MADERA

Utensilios necesarios para reparar y trabajar morteros y concreto.

Fuente: Cartilla Construcciones para haciendas. Cia. Cementos Colombianos, Bogotá, 1937.

\section{El control de la tecnología: las mediaciones culturales y las transferencias tecnológicas en el mundo industrializado}

La medicalización del espacio doméstico es una faceta reciente en un extenso proceso de recomposición que en los siglos $\mathrm{XIX}$ y $\mathrm{XX}$ afecta tanto a las nuevas profesiones como a los remanentes de los antiguos gremios, ambos relacionados con la tradición constructiva del espacio arquitectónico. Previamente se ha identificado por el posicionamiento de la cultura técnica a partir del siglo XVIII, situación que se redefine en los siglos $\mathrm{XIX}$ y $\mathrm{XX}$ con la adopción de discursos extradisciplinares, provenientes de la medicina (higienismo) y de nuevas disciplinas de las ciencias sociales: las incipienes aproximaciones de la psicología y la antropología dirigidas a los usos del espacio habitado (tanto en su componente público, como en el privado). Esta dinámica se encauza en varios frentes: una redifinición de la evolución tecnológica que contemple los distintos ciclos y técnicas que participan en el soporte material del espacio habitable; otra historia de la técnica que no se relaciona con lo constructivo pero que sí lo afecta: los procesos de extensión en la transmisión del saber técnico y la recomposición de la imagen técnica por la aparición de estrategias didácticas.

Fig. 8 En pleno siglo XX técnicas constructivas de punta como el concreto seguirán empleando herramientas, métodos y recursos distantes de la fordización que se aplica fuera de las fábricas, en los demás ámbitos de la vida cotidiana.

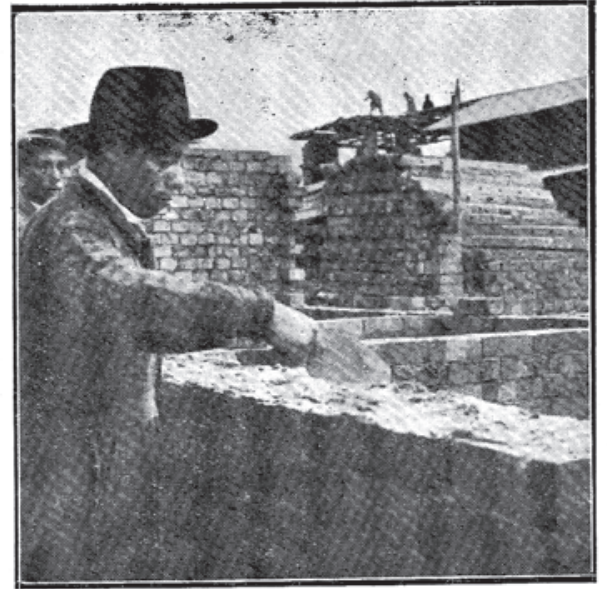

Fuente: Revista Cemento N 8. Cia. Distribuidora de Cementos Colombianos, Bogotá, septiembre de 1937. 
En primer lugar, la definición de las eras del desarrollo de la técnica, abarcando tanto aquellas que se actualizan con mayor versatilidad ( $p . e j$. aquellas relacionadas con la dotación de la parafernalia doméstica) y otras que consolidan el soporte material de la vida cotidiana (p.ej. las técnicas de la construcción -independientemente del tema de los estilos arquitectónicos y artísticos vigentes para un lapso histórico determinado), las cuales se actualizan o reemplazan con mayor lentitud (en parte por los ciclos productivos y económicos, en parte por dificultades en la capacitación de la mano de obra, pero también por resistencias tanto de los usuarios como de los constructores para acoger nuevos sistemas constructivos).

En Técnica y Civilización, Lewis Mumford plantea que el desarrollo tecnológico occidental no es identificable exclusivamente a partir de la aparición de las diferentes creaciones que constituyen la alianza progreso-mecanización: la historia de la técnica-especialmente aquella que afecta la esfera occidental- no puede constituirse sólo como un recuento cronológico de inventos y procesos; asimismo, esta mecanización de los cuerpos, las costumbres y los ritmos vitales no es un logro inmediatamente relacionable con la Revolución Industrial, principal foco de atracción para algunos historiadores de la técnica. Para desarrollar su historia de la evolución técnica, Mumford introduce un concepto crucial: el complejo técnico, resultante de las relaciones más o menos acertadas entre los modos de producción, la obtención de fuentes de energía y materias primas y los modos de consumo.

A diferencia de las propuestas marxistas, Mumford reconoce factores diferentes al económico como incidentes en el éxito o fracaso de un logro técnico: las prácticas culturales que hacen viable la asimilación de un invento o de un avance técnico dentro del complejo social. El propósito consiste en "estimar los productos derivados sociales y culturales de los desarrollos técnicos (...)al presentar el desarrollo técnico dentro de una ecología social más general" [Mumford, I7].

No basta con desarrollar una innovación potencialmente decisiva para el desarrollo de la sociedad, si ésta no se incorpora por los agentes necesarios para el circuito de producciónconsumo; los aparatos, procesos y máquinas innovadoras no son socialmente eficientes si no generan nuevos hábitos o si modifican las costumbres de algunos colectivos significativos en un determinado momento histórico. El complejo técnico relacionará la obtención de recursos y materias primas, la facilidad de conseguir, controlar y acumular las fuentes de energía, así como también las técnicas para manipular dichos recursos. De manera paralela a la constitución del primer complejo técnico, que permite hacer la transición del mundo antiguo a las sociedades protomodernas, se dan los pasos de la regimentación que afecta las prácticas culturales y que generan tendencias en las costumbres e ideales comunes para una sociedad en una época en particular.

El complejo técnico es el resultado de asociar el grado de especialización y el grado de impersonalidad que pueden obtenerse en las herramientas, objetos y máquinas en un momento histórico determinado; este perfil cada vez más especializado y la autonomía con respecto a la fuerza motriz bruta y/o la mano humana, está correlacionado también con el dominio de la obtención y acumulación de la energía para su uso a posteriori; en otros términos: ¿Cómo independizar el trabajo de la fuerza bruta, situación que implica una relación directa y momentánea entre fuente de energía y máquina o aparato? ¿Cómo hacer eficientes, constantes y controlables las fuentes de energía, aún en momentos en que no se requieren para la producción? Mumford jerarquiza los logros técnicos desde los más elementales utensilios, muchos de ellos relacionados con circuitos de producción de baja complejidad y, también, con la vida cotidiana. En una escala intermedia estarán los aparatos, aquellos que aumentan la especialización y la impersonalidad, potenciando 
las fuerzas y mejorando los movimientos corporales. En el extremo opuesto, en la escala más alta, estarán las máquinas como tales: la máquina-herramienta será el punto de comparación, en la medida en que es una máquina creada solamente para producir herramientas, e incluso otras máquinas. Una máquina será más avanzada en la medida en que facilite los procesos sin depender de la mano de obra humana, ofreciendo productos cada vez más elaborados y con funciones cada vez más definidas.

Fig. 9 En los procesos civilizatorios, el desarrollo tecnológico invertirá las relaciones entre campo y ciudad a partir de la utilización polivalente de las técnicas asociadas con las infraestructuras y las artes edificatorias: los mismos materiales y técnicas de vanguardia podrán emplearse en lo urbano y lo rural.

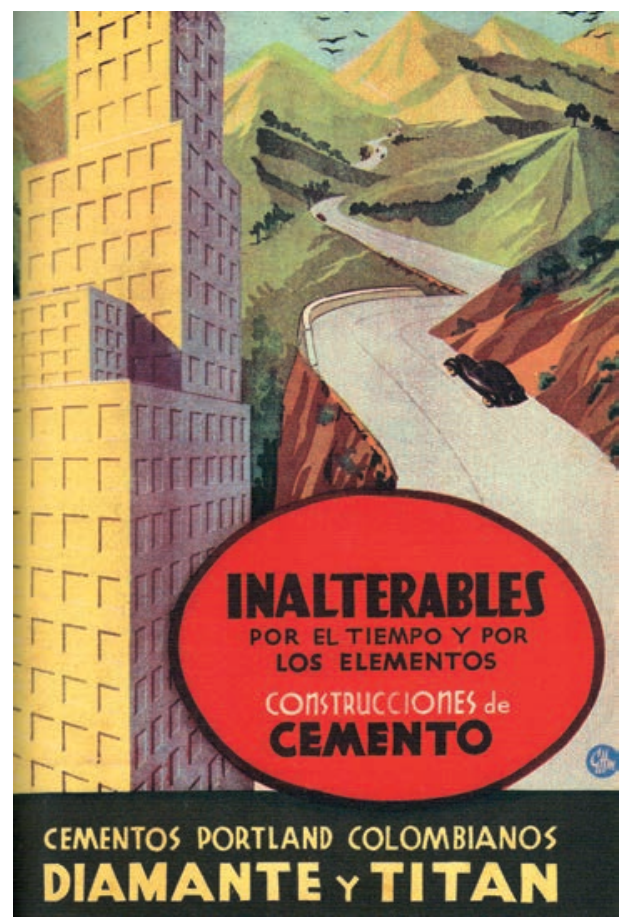

Fuente: Revista Cemento No 7. Cia. Distribuidora de Cementos Colombianos, Bogotá, agosto de 1937

Mumford señala tres estadios que asocian temporalmente la mecanización y la regimentación a través del complejo técnico: una era inicial de la mecanización -que no nesariamente implica la producción de máquinas, pero sí de procesos y hábitos favorables a la mecanización, denominada Era Eotécnica; una Era Paleotécnica coincidente con los grandes logros de la industrialización pero igualmente reconocible por el deterioro de los recursos ambientales y de la calidad de vida de las clases trabajadoras; finalmente, una Era Neotécnica favorable a los derechos ambientales y los discursos de la sostenibilidad, vigentes en la situación contemporánea. Podría asociarse el concepto de mecanización en Mumford con el de control de los procesos naturales no humanos de Elias y de la misma manera, el de regimentación del primero con el control de las relaciones interpersonales del segundo (aunque también incluiría parte de las estrategias de autocontrol, ya que la regimentación afecta tanto los hábitos colectivos como los individuales).

El momento anticipatorio o Era Eotécnica se reconoce a partir del siglo $X$ d.C. con inventos que alivian la fuerza humana y/o animal como únicas fuentes de energía para la producción: los primeros intentos para obtener fuentes de energía continuas y estables a partir del agua, el viento y algunos productos de la minería. Surgen las primeras máquinas para medir el tiempo como los relojes de agua y arena, pero su aparición no habría sido 
exitosa sin su aplicación práctica en la segmentación de las labores y actividades diarias (p.ej. el fraccionamiento racional de los días y semanas gracias a la relación entre el reloj y la campana en los monasterios de clausura medievales). El primer momento del desarrollo técnico se caracteriza por un control más eficaz de las fuentes de energía externas al hombre y a los animales de tracción, pero también por definir los hábitos gracias a un dominio cada vez más exacto del tiempo:

Expresándonos en términos de energía y materiales característicos, la fase eotécnica es un complejo de agua y madera: la fase paleotécnica es un complejo carbón y hierro, y la neotécnica es un complejo electricidad y aleación. La gran contribución de Marx como economista sociólogo fue el ver y en parte demostrar que cada período de invención y producción tenía su propio valor específico para la civilización, o como él hubiera dicho, su propia misión histórica. No puede divorciarse la máquina de su más amplio patrón social, porque es este patrón el que le da significado y finalidad. Cada período de la civilización lleva dentro de sí el insignificante desecho de tecnologías pasadas y el germen importante de otras nuevas: pero el centro de desarrollo se encuentra dentro de su propio complejo. [Mumford, 129. El subrayado es del autor]

Este proceso preparatorio de regimentación, anterior a la mecanización característica de las revoluciones industriales de los siglos XVIII y XIX instaura tendencias, actitudes y cambios radicales en las costumbres ancestrales de los pueblos anteriormente marcados por los ritmos naturales; se caracteriza por la inclusión de nuevos ciclos y procesos abstractos -por tanto anti-naturales- que comienzan con la medida del tiempo sin la presencia necesaria de mecanismos asociados con la relojería. La regimentación se asocia con la disciplina militar pero, según el planteamiento de Mumford, se desarrolla inicialmente en los monasterios y luego es transferida a los cuarteles, especialmente cuando se conforman los primeros ejércitos profesionales de los estados protomodernos:

El monasterio fue la sede de una vida regular, y un instrumento para dar las horas a intervalos o para redordar al campanero que era hora de tocar las campanas es un producto casi inevitable de esta vida. Si el reloj mecánico no apareció hasta que las ciudades del siglo XIII exigieron una rutina metódica, el hábito del orden mismo y de la regulación formal de la sucesión, se había convertido en una segunda naturaleza en el monasterio. [Mumford, 30]

La regimentación en Mumford constituye la antesala de la mecanización aplicada a la vida urbana; es el resultado de la confluencia de varios procesos: el control del tiempo asociado con los ciclos corporales y los hábitos; la segmentación de los ciclos y fenómenos naturales; en Elias, el dominio de aquellas manifestaciones de la agresividad -asociadas con el componente animal del género humano- para resolver los conflictos del orden humano-social en el ámbito público y el control de las pulsiones en los entornos domésticos. El uso decididamente razonado de los procesos naturales será asumido en el Estado moderno por una serie de disciplinas cada vez más especializadas, repartiendo sus áreas de acción en el control de las pulsiones: los procesos fisiológicos (el dominio de las secreciones corporales en la escuela y el hogar, el manejo de una salud pública para evitar la propagación de enfermedades), otros de índole moral y psicológica en la supresión de las manifestaciones irrefrenadas de deseos, temores e impulsos (el componente sexual de las pulsiones, en términos de Elías).

El segundo momento del desarrollo técnico, denominado por Lewis Mumford como la Era Paleotécnica abarca las dos revoluciones industriales; su punto álgido estará entre la Revolución Industrial del siglo XVIII y la siguiente que se extenderá globalmente. 


\section{Particularidades de la tecnificación de los medios constructivos en la Era Paleotécnica}

En la historia del desarrollo tecnológico característico del siglo $X X$ ocurren dos singularidades: en primer lugar, la masificación del confort en virtud la implementación técnica no es una consecuencia directa de los inventos efectuados en dicho siglo; son el resultado de una larga tradición que para el siglo XIX avanzará notablemente con la sociedad victoriana. En segundo lugar, el desarrollo tecnológico no dependerá exclusivamente de la relación entre los medios industrializados y su apropiación recíproca por la cultura de élite y la cultura técnica: aparecerán, desde el siglo XIX, nuevos actores y medios de difusión que harán cada vez más amplio el rango de cobertura de estos inventos que afectan la vida cotidiana. El espacio doméstico será poblado -o al menos así se pretenderá- por los productos de esta mecanización, así como también por aparatos a la escala de las actividades de la vida cotidiana: las funciones del baño y de la cocina serán los principales objetivos de esta tecnificación.

Pero tanto la élite dirigente como la cultura técnica del siglo XX detectan que la mejoría en los estándares de vida deben extenderse a todos los sectores productivos de la sociedad, especialmente a las clases populares. Por una parte habrá que adecuar estas tecnologías del confort a las capacidades de estos estratos, pero de otra parte los oficios constructivos siguen siendo artes del hacer con las manos. En las periferias aún se seguirá construyendo con métodos artesanales o con procesos de racionalización técnica de baja complejidad (como en el caso de la mampostería y sistemas similares que combinan modulación, prefabricación simple, pero a la vez procesamiento y/o aplicación artesanales). Pronto se crerará la conciencia de que estos procesos de mecanización no son viables mientras no se sustituyan los modos de producción tradicionales, situación que no se realiza de una manera expedita: aquel "insignificante desecho de tecnologías pasadas" que mencionaba Mumford, en la primera mitad del siglo XX ni es insignificante ni es residual en las artes constructivas que todavía dependen de la manipulación directa de los materiales por operarios de escasa capacitación, que aún asocian la estandarización con la tradicional

Fig. $10 \mathrm{El}$ voluntarismo de la época brindará la confianza -no siempre fundada- en la capacidad de la técnica para dominar aquellos procesos naturales no humanos, incluyendo aquellos fenómenos que desbordan la capacidad de dominio y la posibilidad de anticiparlos.

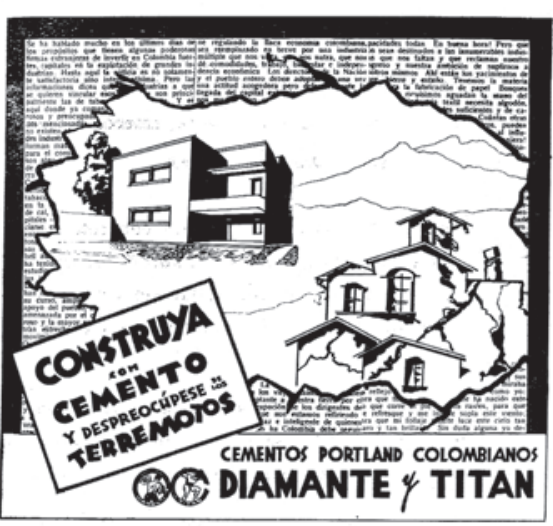

Fuente: Revista Cemento $N^{\circ}$ 8. Cia. Distribuidora de Cementos Colombianos, Bogotá, septiembre de 1937.
Fig. I I Las políticas higienistas popularizán las técnicas asociadas con los materiales que dominan: por ejemplo, el "cemento" será reconocido como un elemento que aporta limpieza y salud; de esta manera se "higienizarán" tanto la casa como el paisaje, lo urbano y lo rural.

\section{PAVIMENTOS DE CONCRETO}

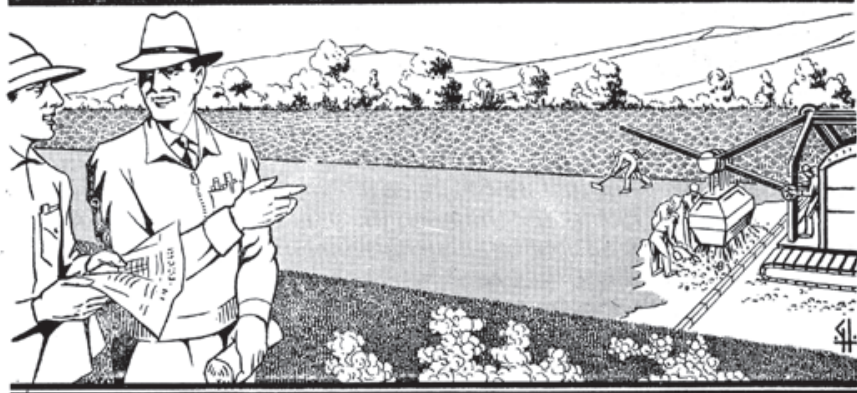

DURABLES - ECONOMICOS - LIMPIOS HIGIEnICOS - sEGUROS

Fuente: Revista Cemento N 8. Cia. Distribuidora de Cementos Colombianos, Bogotá, junio de 1937. 
modulación de la mampostería (y su origen artesanal). Si bien se señalan las conductas que deterioran la producción -aquellos ilegalismos menores como la holgazanería y el vagabundeo o, en general, el acto de extraerse del circuito productivo- de otra parte se buscará mejorar las facilidades de quienes sí laboran, no solamente en sus lugares de trabajo sino también en sus recintos cotidianos.

Es probable que en los principales núcleos del mundo industrializado ya sea una constante la mecanización, pero en las periferias continuará esa resistencia frente a la taylorización, la producción serializada y masiva, por razones culturales, económicas y productivas. Adicionalmente, con excepción de la prefabricación y auge de los sistemas modulares en el medio norteamericano -tanto en los métodos edificatorios que emplean la madera y el acero- y los intentos por masificar racionalmente la producción de la vivienda obrera en la Europa en los periodos anterior y posterior a la Segunda Guerra Mundial, en otros contextos, los oficios constructivos se resisten a tales intentos. Aún en los casos en que se realicen grandes proyectos de vivienda masificada, la producción parcial o total de ellos se seguirá haciendo mediante las técnicas tradicionales que son actualizadas, mas no reemplazadas en su totalidad por sistemas integralmente industrializados.

Las mediaciones culturales en el medio técnico del espacio doméstico pretenderán paliar las diferencias entre la especialización e independencia de la mano de obra de la industria - cadena de montaje y las deseconomías y atrasos de algunas prácticas de los oficios constructivos, en cierta medida muy especializados pero dependientes de operarios (no siempre en condiciones óptimas de capacitación) que ejecutan directamente los procesos. ¿Cómo hacer más eficientes las técnicas tradicionales, cuando éstas no pueden ser sustituidas completamente por las tecnologías de punta? ¿Cómo participa esta cultura técnica en la definición de códigos de conducta y parámetros de control social que afectan los modos de habitar del siglo $\mathrm{XX}$ ?

Aquí se asumirá desarrollo tecnológico no sólo como el conjunto de logros que hacen más eficiente la mecanización de la vida productiva: no se trata exclusivamente de identificar y relacionar la aparición de los inventos, sino cómo las innovaciones son incorporadas dentro de la vida social; cómo los logros técnicos afectan la vida comunitaria y la vida privada, afectando los códigos de comportamiento y generando nuevos protocolos de conducta. Por evolución de la organización social en el siglo $\mathrm{XX}$, un proceso paralelo a la ya extendida mecanización heredada de las revoluciones industriales precedentes, se entenderán las mediaciones culturales resultantes de la serie de actitudes, estrategias, tensiones y dinámicas que generará la cultura técnica en su consolidación como actor social frente a la manida disputa entre cultura de élite y cultura popular, bosquejada desde el Romanticismo. El proceso civilizatorio extendido a la respuesta que los gremios técnicos ofrecen a las nuevas prácticas sociales que requieren de una vida "sana y ordenada" en las clases populares

La transmisión del saber técnico, su énfasis en la extensión hacia colectivos originalmente no incluidos en su definición, es una tendencia que no puede desvincularse de la conformación misma de la imagen técnica: ¿Qué recursos aplican en las técnicas de representación y en las técnicas constructivas para materializar y divulgar el credo moderno del espacio higiénico? ¿Cómo relacionan los espacios propuestos con las conductas y usos que los usuarios deben adoptar en ellos?
Fig. 12 La adopción de hábitos modernos extiende el higienismo más allá de la salud corporal, saltando también de lo íntimo al mundo de las relaciones sociales: la salud mental se asociará con la adecuada disposición del ocio y del tiempo libre, temáticas que interesarán a las élites, las clases medias y obreras, buscando calidad de vida.

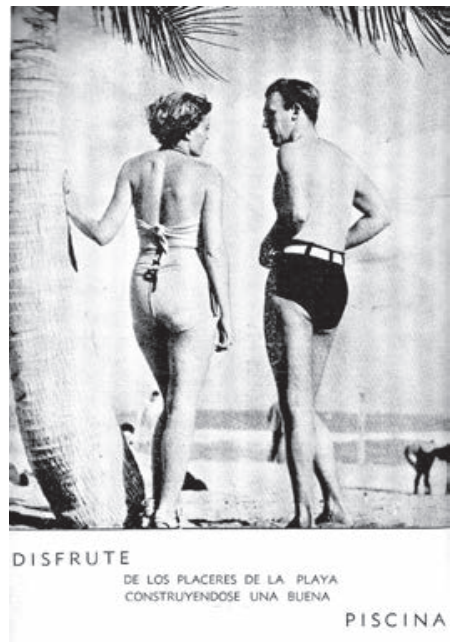

Fuente: Revista Cemento $N^{\circ}$ 5. Cia. Distribuidora de Cementos Colombianos, Bogotá, junio de 1937 


\section{La reconstitución de la imagen técnica como mediación cultural}

En un breve ensayo titulado Las láminas de la Enciclopedia el semiólogo estructuralista francés Roland Barhtes (1915-1980) plantea dos propósitos de especial interés para esta investigación: de un lado, una lectura semiológica de la imagen - específicamente de la imagen técnica- asumida también como lenguaje articulado. Aquí Barthes traslada su teoría de la comunicación del mundo del lenguaje escrito -particularmente el literario- al mundo de la imagen; de otro lado, constituir en objeto de estudio el componente gráfico de la Enciclopedia francesa, destacando su estructura comunicativa-visual en virtud de su correspondencia con el enfoque ideológico del Positivismo europeo. A partir de este momento se crea una tendencia en la producción tecnológica, tendencia que buscará vincular el objeto producido de manera mecánica (en la medida de sus posibilidades), la imagen que representa este proceso y una ideología en la que la mecanización brinda una condición de dominio del mundo natural:

(...) Mucho antes que la literatura, la Enciclopedia, especialmente en sus láminas, practica lo que podría llamarse una cierta filosofía del objeto: es decir que reflexiona sobre su ser, opera simultáneamente un recuento y una definición. Es cierto que el dibujo tecnológico obligaba a describir los objetos pero, separando las imágenes del texto, la Enciclopedia asumía una iconografía autónoma del objeto -cuyo poder sólo saboreamos hoy- puesto que de esta manera estas ilustraciones no son observadas como una pura mostración del saber. Éste es el fenómeno que queremos mostrar aquí. [Barthes, 123]

Fig. 13 La medicalización de la vida íntima no proscribe únicamente aquellas malas prácticas culturales que minan la salud corporal; también señala conductas moralmente impropias (la promiscuidad y el incesto) y aquellas relacionadas con usos abusivos del espacio (el hacinamiento, los inquilinatos y la utilización compartida de dormitorios por sexos diferentes). Se proponen tipologías que alteren estas conductas pero que conserven la imagen tradicional de la vivienda popular.
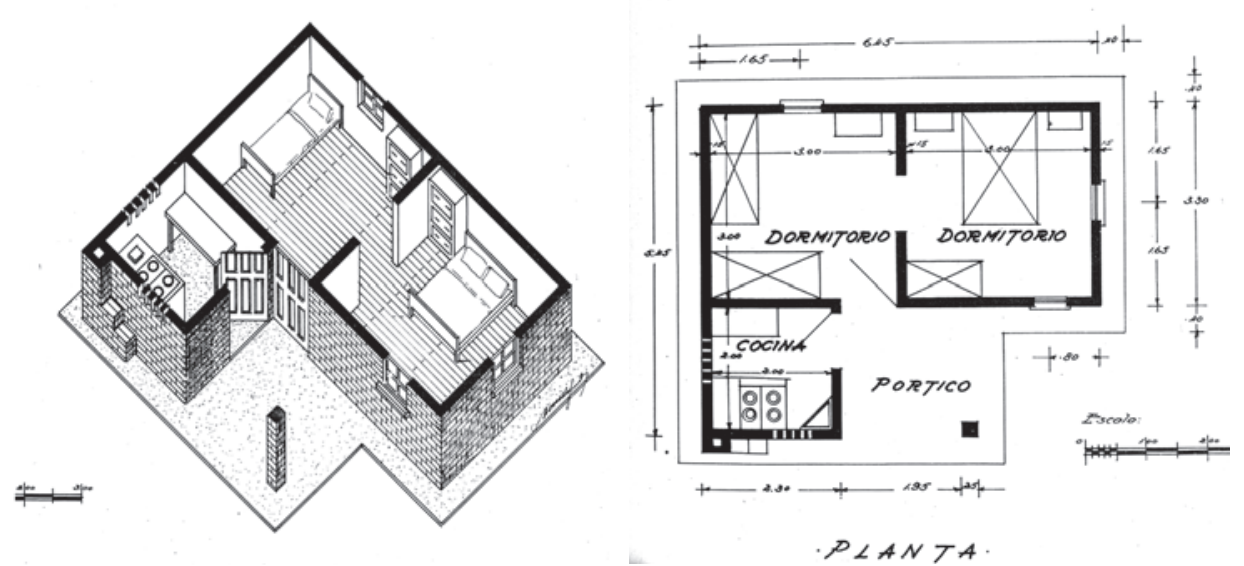

Fuente: Cartilla de Construcciones Rurales, Alberto Wills Ferro, INSCREDIAL, Bogotá, 1946

Pero más importante aún es el tópico que Barthes identifica a partir de este objeto de estudio: la imagen enciclopédica marca una inflexión en el modo de representar el objeto técnico al introducir un proceso analítico-visual que tiene por soporte material un medio de divulgación característico de la cultura técnica moderna: los libros. Podría afirmarse que el origen de la genealogía que se pretende enunciar aquí no parte de los antiguos tratados medievales de artes aplicadas ni de la imagen técnica consolidada con los tratados renacentistas de los oficios; su núcleo de estudio radicaría en la configuración del género de las literaturas técnicas y de las literaturas de extensión o divulgadoras, éstas últimas como variaciones de las primeras. 
Fig. I4 Por una parte una imagen conciliatoria de la vivienda rural "higienizada" física y moralmente que busca empatía con los usuarios de las clases populares; de otra parte, disposiciones espaciales al interior que rompen las relaciones tradicionales entre los distintos componentes de la casa rural: padres e hijos se separan en sus respectivas habitaciones (así como hombres y mujeres), pero la cocina, aquel lugar de socialización familiar, se aísla del resto de estancias.

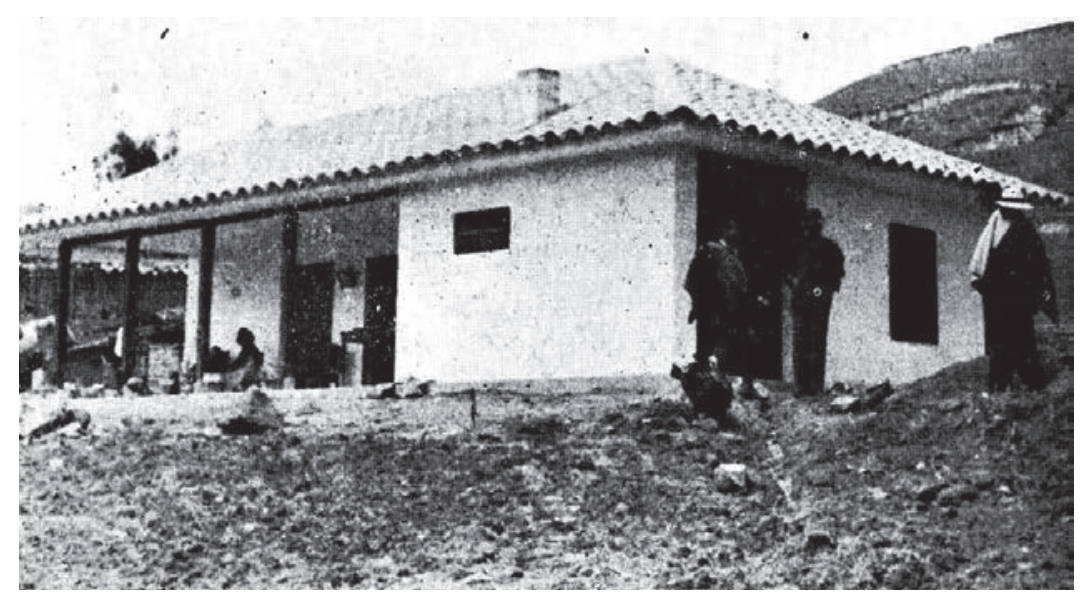

Fuente: Cartilla de Construcciones Rurales, Alberto Wills Ferro, INSCREDIAL, Bogotá, 1946

Del texto de Barthes se deducen y enfatizan cuatro aspectos: el primero, la correlación entre una lectura histórica de los estadios técnicos que definen el mundo moderno y la historia del saber: ¿Cómo relacionar la historia de la mecanización con la historia de las ideas? En segundo lugar, las primeras manifestaciones de las mediaciones culturales: cómo la difusión del saber característico de la ciencia y de la técnica se propaga a través de los medios impresos, que actúan simultáneamente como soporte material y método analítico (para el usuario contemporáneo a aquellos) y objeto de estudio (para el investigador actual). En tercer lugar, la posibilidad de enunciar una genealogía de las literaturas técnicas que tendría su origen en los escasos libros conservados de oficios artesanales de la Edad Media, continuando con los tratados disciplinares renacentistas, pasando por el enfoque que define su proximidad con la cultura técnica moderna a partir de las láminas enciclopedistas; para concluir con los textos de instrucciones gráficas masificados en los siglos $\mathrm{XIX}$ y $\mathrm{XX}$. Como consecuencia de los anteriores, el cuarto y último tópico se refiere a la innovación que introduce el espíritu de la llustración en el círculo de las literaturas técnicas al convertirlas en mediaciones culturales dada su estructura abierta, no secreta y divulgativa de un saber especializado que ahora se "contamina" con discursos de otras disciplinas como la medicina y de ideologías conductistas y moralistas.

Fig. I5 Cuando los medios técnicos de la higienización son inalcanzables en las periferias, se opta por soluciones alternas en las que sus materias primas y las herramientas empleadas en su fabricación poseen bajos grados de especialización y de impersonalidad.

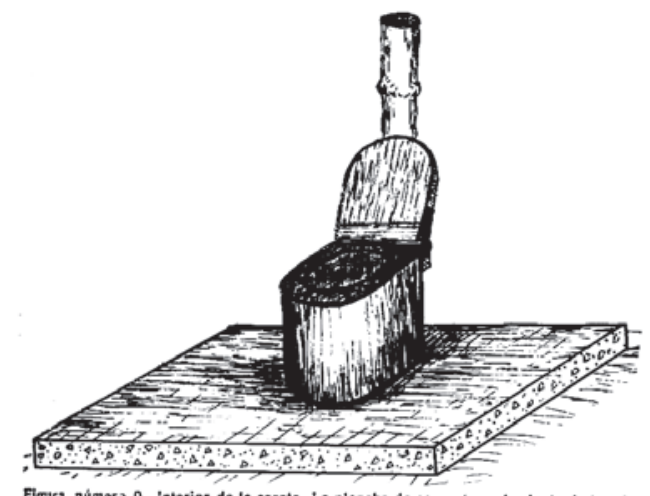

Figura númers 9-interior de la caseta. La plancha de concreto y el asiento de to mis-
moi con su obra de madera, ya terminados. Ossérrevese la posición de la tapa al apoyar-
se en el tubo de ventiliación.

Fuente: Revista Salud y Sanidad N³8-39. Ministerio de Salud, Bogotá, febrero-marzo de 1935. 
Las láminas de la Enciclopedia marcan la divergencia entre un estadio tecnológico que desea superarse -una voluntad de nuevos modos de producción, pero también de nuevas modalidades de consumo- en un momento en el que las tendencias ideológicas del Positivismo filosófico ya estaban más definidas, al menos en el ámbito de la alta cultura. Estas publicaciones marcan la tendencia de dominio del mundo natural y social a partir de una técnica "tranquilizadora":

Constantemente la Enciclopedia da un testimonio de una cierta epopeya de la materia, pero esta epopeya es también de alguna manera la del espíritu: el trayecto de la materia no es otra cosa para el enciclopedista que el encaminarse de la razón: la imagen tiene también una función lógica. [Barthes, 137]

\section{Breve genealogía de la imagen en las literaturas técnicas}

El gran aporte de la dialéctica visual enciclopedista al circuito de las literaturas técnicas y al método de representación de las instrucciones gráficas radica en introducir momentáneamente el universo de lo vivido, plausible en la viñeta, en los medios impresos especializados que anteriormente se centraban en una representación "paradigmática" y taxonómica -en términos de Barhtes- de los procesos de fabricación de los objetos. Al mostrar separadamente, pero dentro de una misma página, la viñeta/sintagma y el objeto aislado/paradigma, la diagramación de los enciclopedistas relaciona dos modos representacionales de la imagen y dos metodos de análisis que antes y después de la Ilustración se mantendrán relativamente independientes.

En el siglo XIX la industria del grabado y los grandes medios masivos editoriales facilitarán una tecnología de la imagen cada vez más fluida en su capacidad de generar imágenes: por una parte la representación del objeto mecánico será más precisa (ya sea en su uso genético o en el anecdótico) mientras que la viñeta se especializará en las grandes descripciones del mundo natural (de tipo "científico"), en las visiones costumbristas de entornos sociales y de colectivos "distintos" (las primeras lecturas antropológicas desde la imagen) y en la caricatura o exageración de rasgos, fisonomías, pero también defectos, hábitos y conductas (tanto colectivas como individuales).

Fig. 16 En el extremo opuesto, las tecnologías del confort hacen que la vida privada utilice dispositivos de mayor complejidad en su dotación: el espacio doméstico, al igual que las herramientas y máquinas, adquiere mayor grado de especialización.

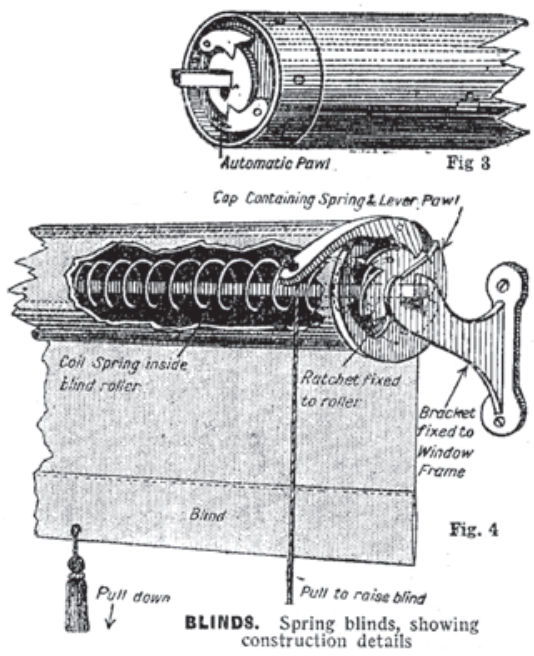

Fuente: Home Furnishing and Decoration, Londres, 1933? 
Figs. 17 y 18 Dos facetas del énfasis de la imagen técnica en el siglo XX: un uso paradigmático de las técnicas higienistas que muestra el cómo se fabrica y cómo funciona; de otro lado, la fotografía asume el uso sintagmático con la puesta en escena de los objetos, función que anteriormente resolvía la viñeta en la imagen enciclopedista.

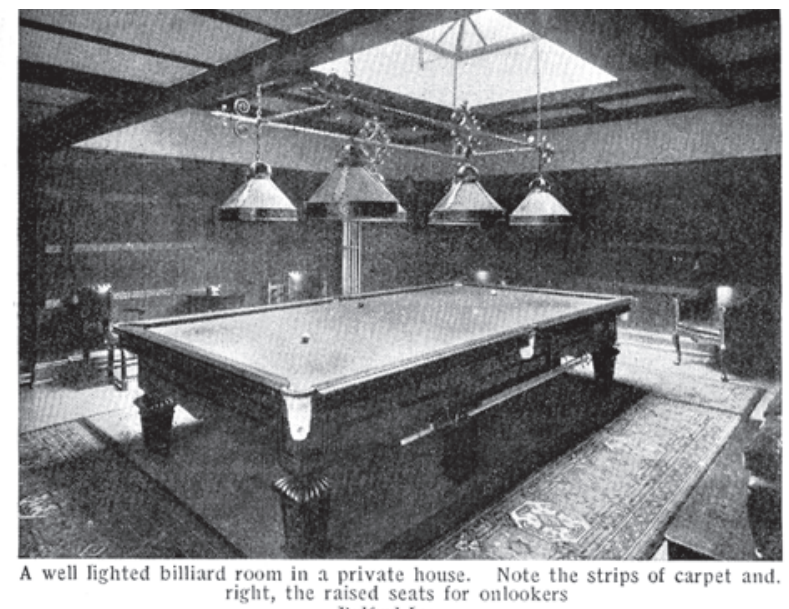
right, the raised seats for
Belfowl Lemere
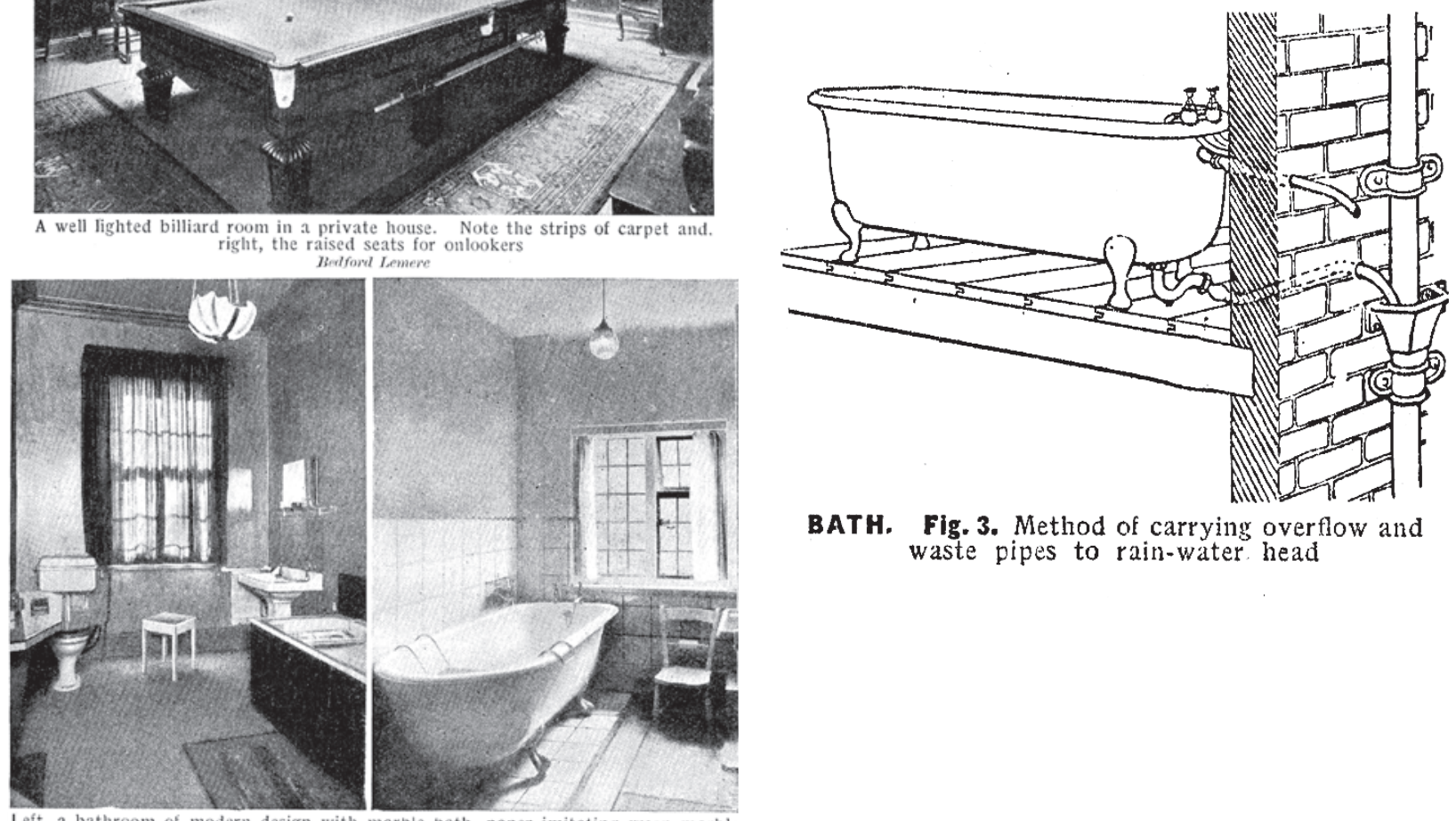

BATH. Fig. 3. Method of carrying overflow and waste pipes to rain-water head

Left, a bathroom of modern design with marble bath, paper imitating green marbl tiled dado and coloured walls and floor BILLIARD ROOM AND BATHROOMS

Volume I

Fuente: Home Furnishing and Decoration, Londres, 1933?

Las tecnologías de la imagen, algunas aparecidas a finales del siglo XIX y otras plenamente desarrolladas en el siglo $\mathrm{XX}$, llevarán al extremo el uso antológico y el anecdótico. La fotografía acentuará el carácter antológico, aunque no necesariamente entrará en disputa con la caricatura ni con la imagen costumbrista (unas y otras se complementarán: la caricatura por su capacidad de síntesis y exageración de lo que se quiere enfatizar; la viñeta costumbrista al poner en contexto una situación o un tópico para facilitar su consumo a los colectivos/usuarios a los que se dirige la publicación; la fotografía en su carácter indexical por su capacidad de corroborar, de brindar ejemplos en un uso casi "notarial").

En la primera mitad del siglo $\mathrm{XX}$ los medios impresos de divulgación que contribuyen a que la cultura técnica se constituya en mediador cultural entre la élite dirigente y las clases populares adoptan las siguientes modalidades: un medio ampliamente conocido del saber técnico, pero con algunas modificaciones: el manual; $y$ otros de corte masivo: la cartilla, la revista, la propaganda, el manifiesto, el decálogo y las instrucciones de uso. 


\section{La problemática de las duraciones históricas en la Historia del saber técnico}

La definición de duraciones históricas específicas para el estudio del desarrollo tecnológico se complejiza cuando se entrecruzan las condiciones endógenas o internas (el surgimiento de determinadas innovaciones, los cambios radicales en los procesos productivos, el colapso o decadencia de los antiguos modos de producción y de consumo) con las circunstancias externas: los ciclos políticos, económicos y su posible correspondencia con periodos artísticos. Como se mencionó anteriormente, la Historia de la técnica puede operar con ciclos diferentes a los intervalos políticos y artísticos, aunque no puede independizarse completamente de los ciclos económicos ni de las prácticas culturales que hacen viable un logro tecnológico en un momento histórico dado.

En el caso de la Enciclopedia se puede marcar un momento de transición e incertidumbre entre los antiguos oficios artesanales y la nueva era industrial que se avecina, pero que aún no permea el contexto social en el cual se pretende desempeñar; asimismo, los planteamientos ideológicos y estéticos que competen a la Historia de las Ideas intentan instaurar un nuevo método científico positivista que encuentra profundas resistencias en los ámbitos que integran la sociedad europea. Barthes reconoce esta transición de los diferentes estadios técnicos, muy similar a la definición de la Era Eotécnica tal como la delimita Lewis Mumford (un complejo técnico de madera, agua, carbón; objetos, máquinas y herramientas que todavía dependen del control la mano humana; la producción de energía externa a la máquina -y dependiente de la fuerza bruta, ya sea humana o animal, sumada a una incipiente capacidad de acumular dicha energía):

[] El objeto enciclopédico es producto de materias generales que son aún las de la era artesanal. Si visitamos hoy día una exposición internacional percibiremos a través de todos los objetos expuestos dos o tres materias dominantes, vidrio, metal, plástico sin duda; la materia del objeto enciclopédico es de una edad más vegetal: es la madera la que domina en este gran catálogo construyendo un mundo de objetos dulces a la mirada, humanos ya por su materia, resistente pero no áspera, maleable pero no plástica. Nada muestra mejor ese poder de humanización de la madera que las máquinas de la Enciclopedia; en este mundo de la técnica (todavía artesanal pues la gran industria no ha nacido aún), la máquina es un objeto capital y la mayor parte de las máquinas de la Enciclopedia están hechas de madera; son enormes andamios, muy complicados, en los cuales el metal sólo provee las ruedas dentadas. La madera que las constituye las vincula a una cierta idea del juego: esas máquinas son (para nosotros) como grandes juguetes; inversamente a las imágenes modernas, el hombre, siempre presente en algún rincón de la máquina, no tiene con ella sólo una relación de vigilancia [Barthes, I25-I26]

Barthes identifica una relación consonante, libre de tensiones, entre el mundo de la producción y el mundo del consumo basada en la simplicidad y confianza de los logros técnicos:

(...) la máquina enciclopédica es sólo una gran mediación: el hombre está en un punto, el objeto en el otro, entre los dos, un ambiente arquitectónico -hecho de postes, cuerdas y ruedas- a través del cual, como una luz, la fuerza humana se desarrolla, se concentra, aumenta y se precisa simultáneamente (...) No se puede tener una idea más simple de la técnica.

Simplicidad casi ingenua, una forma de la leyenda dorada del artesanado (pues no hay en estas láminas ningún rastro del mal social): la Enciclopedia confunde lo simple, lo elemental, lo esencial y lo causal. La técnica enciclopédica es simple porque está reducida a un espacio con sólo dos términos: es el trayecto causal que va de la materia al objeto; también todas las 
láminas que presentan alguna operación técnica (de transformación) movilizan una estética de la desnudez: grandes piezas vacías, bien iluminadas, donde sólo cohabitan el hombre y su trabajo: espacio sin objetos parasitarios, de paredes desnudas, de tablas rasas; aquí lo simple no es otra cosa que lo vital; (...) De una manera general, la producción del objeto arrastra la imagen hacia una simplicidad casi sagrada; por el contrario su uso (representado en el momento de la venta, en el negocio) autoriza un embellecimiento de la viñeta, abundante en instrumentos, accesorios y actitudes: austeridad de la creación, lujo del comercio, tal es el doble régimen del objeto enciclopédico: la densidad de la imagen, su carga ornamental significa siempre que se pasa de la producción al consumo. [Barthes, I27-I28]

Fig. 19 Entrado el siglo XX, buena parte de los utensilios, herramientas e instrumentos empleados en la construcción se mantienen alejados de los principios de la mecanización, semejándose a sus antecesores de la era eotécnica: pueden tener un alto grado de especialización pero también un bajo grado de impersonalidad y escasa capacidad de acumular energía, en la medida en que todavía dependen de la fuerza bruta.

Fig. 75.

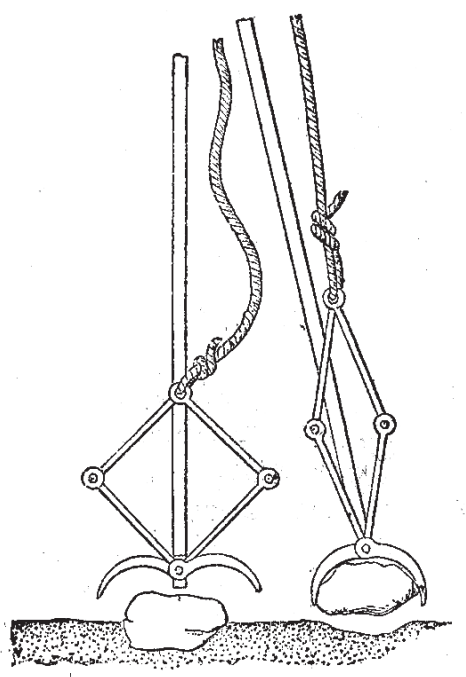

Fuente: CLAUDEL, J. \& LAROQUE, L. PRACTIQUE DE L’ART DE CONSTRUIRE : Maçonnerie, terrasse et platrerie. Paris, 1870.

\section{Niveles de la imagen enciclopédica}

L'Encyclopédie ou Dictionnaire raisonné des sciences, des arts et des métiers en su cuerpo original -bajo la dirección de Denis Diderot y Jean d’Alembert- está integrada por $2 \mathrm{I}$ volúmenes de texto (publicados entre $175 \mathrm{I}$ y 1765 ) y II volúmenes de imágenes publicados cuando ya concluía la parte escrita (I 762-I772). Posteriormente, entre 1776 y I 780, salieron a la luz pública 4 volúmenes de texto, I de láminas y 2 a manera de índice, contando con la supervisión del editor Panckoucke.

El texto de Barthes se remite al componente gráfico o visual de la Enciclopedia; allí reconoce tres niveles o categorías de la imagen:

(...) Este objeto enciclopédico está generalmente representado por la imagen en tres niveles: antológico, cuando el objeto aislado de todo contexto está presentado en sí mismo; anecdótico, cuando está "naturalizado" por su inserción en una gran escena viviente (es lo que se llama la viñeta); genético, cuando la imagen nos proporciona el trayecto que va desde la materia bruta al objeto terminado: génesis, esencia, praxis, el objeto está abordado bajo todas sus categorías: en tanto es, en tanto es hecho y en tanto hace. De esos tres estados asignados al objeto-imagen, uno está claramente privilegiado por la Enciclopedia: el 
del nacimiento: es beneficioso poder mostrar cómo se puede hacer surgir las cosas de su misma inexistencia y acreditarle así al hombre un asombroso poder de creación (...), nacen objetos anticipadores de humanidad (...) Es como un símbolo: el hombre enciclopédico mina la naturaleza entera de signos humanos; en el paisaje enciclopédico no se está nunca solo, en lo más crudo de los elementos hay siempre un producto fraternal del hombre: el objeto es la firma que pone el hombre sobre el mundo. [Barthes, 125. El subrayado es del autor]

\section{Estructura lineal-bipolar}

El componente gráfico de la Enciclopedia se estructura en dos niveles de información que integran cada página: un nivel inferior -que constituye el principal interés metodológico de los enciclopedistas ya que responde visualmente a su método de análisis- "visible" a partir del recurso de la Taxonomía, es señalado por Barthes como el nivel del Paradigma. En el extremo opuesto, un nivel superior correspondiente al Sintagma e identificable por la Viñeta o puesta en escena del objeto de estudio:

Fig. 20 Las láminas enciclopedistas relativas a las artes y oficios emplean de manera más explícita la estructura comunicativa analizada por Barthes; las láminas dedicadas a la construcción, la decoración arquitectónica y las infraestructuras de la ingeniería civil se apoyan más en el componente contextual de la viñeta.

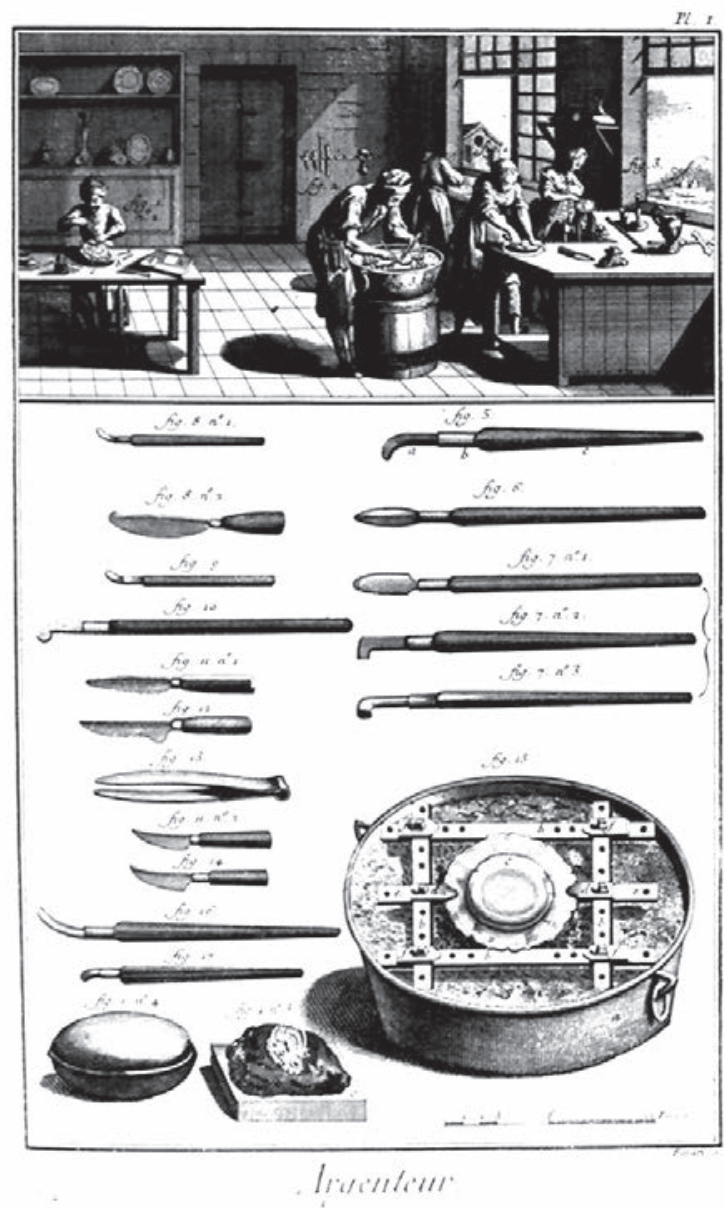

Fuente: DIDEROT et D ALEMBERT. L'Encyclopédie: Quatriéme planche: outils de I'argenteur. 
De esta manera, en el estado inmediato de sus representaciones, la Enciclopedia no deja de familiarizar el mundo de los objetos (que es su materia primera) agregándole la cifra obsesiva del hombre. Sin embargo, más allá de la letra de la imagen, esta humanización implica un sistema intelectual de una extrema sutileza: la imagen enciclopédica es humana no solamente porque en ella figura el hombre sino también porque constituye una estructura de informaciones. Esta estructura, aunque iconográfica, se articula en la mayoría de los casos como el lenguaje natural (al que precisamente denominamos articulado) del que reproduce sus dos dimensiones puestas hoy en claro por la lingüística estructural; se sabe, en efecto, que todo discurso comporta unidades significantes y que esas unidades se ordenan según dos ejes, el de sustitución (paradigmático) y el de contigüidad (o sintagmático); de esta manera cada unidad puede variar (virtualmente) con sus semejantes, y encadenarse (realmente) con sus vecinas. Es lo que ocurre, grosso modo, en una lámina de la Enciclopedia. La mayor parte de estas láminas están formadas de dos partes; en la parte inferior, la herramienta o el gesto (objeto de demostración), aislado de todo contexto real, está mostrado en su esencia; constituye la unidad informativa y esta unidad es, la mayor parte de las veces, variada: se detallan los aspectos, los elementos, las especies; esta parte de la lámina tiene el rol de declinar de alguna forma el objeto, manifestar su paradigma; por el contrario, en la parte superior o viñeta, ese mismo objeto ( $y$ sus variedades) está tomado en una escena viviente (generalmente una escena de venta o de confección, negocio o taller), encadenado a otros objetos en el interior de una situación real: se encuentra aquí la dimensión sintagmática del mensaje; y de la misma manera que en el discurso oral el sistema de la lengua, perceptible sobre todo en el nivel paradigmático, está de alguna manera oculto detrás de la corriente viva de las palabras, de la misma manera la lámina enciclopédica juega a la demostración intelectual (por sus objetos) y a la vida novelesca (por sus escenas). [Barthes, I32-133]

Barthes identifica un carácter no lineal de la imagen enciclopédica, a diferencia de la estructura exclusivamente secuencial / lineal del texto literario. Esta condición es el resultado de un modelo dialéctico más dinámico en su modelo visual que en el textual, ya que este proceso de análisis, descomposición y síntesis puede realizarse de manera más fluida:

(...) El montaje enciclopédico está elaborado racionalmente: desciende tan profundamente como sea necesario en el análisis para “percibir los elementos sin confusión " (según palabras de Diderot (...) (...) la imagen es una especie de sinopsis racional: no solamente ilustra el objeto o su trayecto sino también el espíritu mismo que lo piensa; este doble movimiento corresponde a una doble lectura; si se lee la lámina desde abajo hacia arriba, se obtiene una lectura vivida, se revive el trayecto épico del objeto, su cumplimiento en el complejo mundo de los consumidores: se va de la naturaleza a la socialidad; pero si se lee la imagen desde arriba hacia abajo partiendo de la viñeta, se reproduce el camino del espíritu analítico; el mundo nos da lo usual, lo evidente (es la escena); con el enciclopedista se desciende progresivamente a las causas, a las materias, a los elementos primeros, se va de lo vivido a lo causal, se intelectualiza el objeto. El privilegio de la imagen -opuesta en esto a la escritura que es lineal- es no marcar definitivamente ningún protocolo de lectura: una imagen está siempre privada de vector lógico (experiencias recientes tienden a probarlo); las de la Enciclopedia poseen una preciosa circularidad: se las puede leer a partir de lo vivido, o por el contrario a partir de lo inteligible: el mundo real no está reducido, está suspendido entre dos grandes órdenes de realidad verdaderamente irreductibles. [Barthes, 138-139] 
El desmontaje de las antiguas corporaciones de artesanos medievales no sólo implica cambios en las estructuras de la producción: conlleva también profundas modificaciones en los modos de acumulación de la experiencia y en la transmisión del saber. Induce un redimensionamiento y cambio de estructura de las jerarquías sociales: si los artesanos antes eran asociados con las clases populares de la Edad Media, con la llustración surgirá una nueva cultura técnica que buscará posicionarse a partir de la profesionalización de los antiguos oficios y la aparición de otros anteriormente desconocidos: aparecerá el técnico como clase aparte.

El apuntalamiento en el siglo XX de este Estado moderno conlleva también la consolidación de la cultura técnica que se venía gestando desde la llustración. Ya han cambiado las relaciones que afectan los procesos creativos (el esquema del mecenazgo renacentista), las relaciones en la transmisión del saber y la experiencia (la jerarquía del antiguo esquema del taller medieval) y las transformaciones más evidentes en las relaciones productivas (el fin de los gremios medievales como círculos cerrados que dominan un saber que los hace fuertes y la extensión de la regimentación al mundo productivo, consituyendo a la fábrica como centro productivo).

En el periodo de entreguerras del siglo $X X$ se consolida un proceso que se venía perfilando desde la llustración: la aparición de una cultura técnica que mediará tanto en los medios de producción como en las tensas relaciones entre una élite que ha perdido su origen aristocrático o cortesano y las emergentes clases populares (tanto en su origen obrero, como en el medio rural). El esquema manido de la cultura de élite que perfila las tendencias de una época en pugna constante con las clases populares será afectado por una presencia adicional: las asociaciones de profesionales con formación académica que han recompuesto el antiguo esquema hermético de los gremios medievales de artesanos, antes asociados con las clases populares.

Esta nueva tensión con actores anteriormente no conocidos, o al menos con una presencia no tan definida (como los gremios de profesionales y las clases obreras) hace que se bosquejen nuevas situaciones: la transmisión del saber por medios impresos y por tecnologías de la información alternas, dirigidos a usuarios no necesariamente inscritos en medios académicos u oficialmente formativos; procesos pedagógicos alternos a la relación directa del esquema tradicional profesor-alumno; cambios en los procesos creativos de las profesiones sustentadas en el método de la proyectación; paralelamente a los procesos creativos, la reconsideración de la autoría y del protagonismo del creador frente a una obra de arte/objeto arquitectónico que pierde cada vez más su carácter exclusivo y original; la definición de los gremios técnicos como mediaciones culturales entre la élite y las clases populares, con la introducción consecuente de nuevas tensiones, aciertos y contradicciones.

En resumen, la masificación de las publicaciones que emplean las instrucciones gráficas a manera de mediaciones culturales para suplir las transferencias tecnológicas y la transmisión del saber constructivo son correlativas con el momento álgido de la Era Paleotécnica designada por Lewis Mumford. Responden a la necesidad de cubrir un amplio segmento de usuarios que en la primera mitad del siglo $X X$ no pueden acceder a las tecnologías constructivas de vanguardia (acero-cristal, concreto reforzado), pero que sí podrían adquirir los hábitos "saludables" de la propuesta higienista y -guardadas las proporcioneslas tecnologías del confort de la vida moderna asociadas con el higienismo.

En el siglo XX la medicalización de la vida privada y su divulgación masiva en los diferentes conjuntos que conforman las sociedades occidentalizadas es consecuencia de varias presencias y factores que se generan tiempo atrás: primero, una larga duración definida 
inicialmente por un proceso de regimentación a partir del cual se incorporan procesos y ritmos anti-naturales, generando hábitos condescendientes con la mecanización; segundo, la consolidación de una cultura técnica -en un arco temporal que comienza con el Renacimiento y se acentúa en el siglo XVIII- posicionándose socialmente en la medida en que constituye la credibilidad de sus saberes propios pero que también incorpora discursos pseudocientíficos; tercero, la presencia cada vez más notoria de medios impresos de comunicación que masifican el saber especializado de la cultura técnica (un saber que ya escapa tanto al hermetismo de los antiguos gremios artesanales como a la exclusividad de la élite ilustrada); cuarto, la conversión de la cultura técnica en una mediación cultural por su participación en la popularización de nuevos hábitos y tendencias, resultado de la reconfiguración de los antiguos esquemas sociales por la creciente división del trabajo; quinto, la mediación que aportan estas publicaciones al interior de la cultura técnica por favorecer un consenso entre las posturas radicales de las vanguardias arquitectónicas y las resistencias de las tradiciones constructivas; por último, como parte de estas mediaciones culturales surge un proceso de ficción del usuario del espacio doméstico derivado de la recomposición en la relación entre cliente-arquitecto, arquitecto-usuario (relaciones que se complejizan y adquieren autonomía).

Fig. 2 I En el siglo XX las políticas higienistas - ya sea desde la iniciativa estatal o la de grupos de gestión particulares - reconocerán que no basta con eficientes grupos de profesionales en el campo de la planificación del habitat popular sino que también será vitál el componente propagandístico para facilitar la transición de los habitos en los entornos de la vida privada.

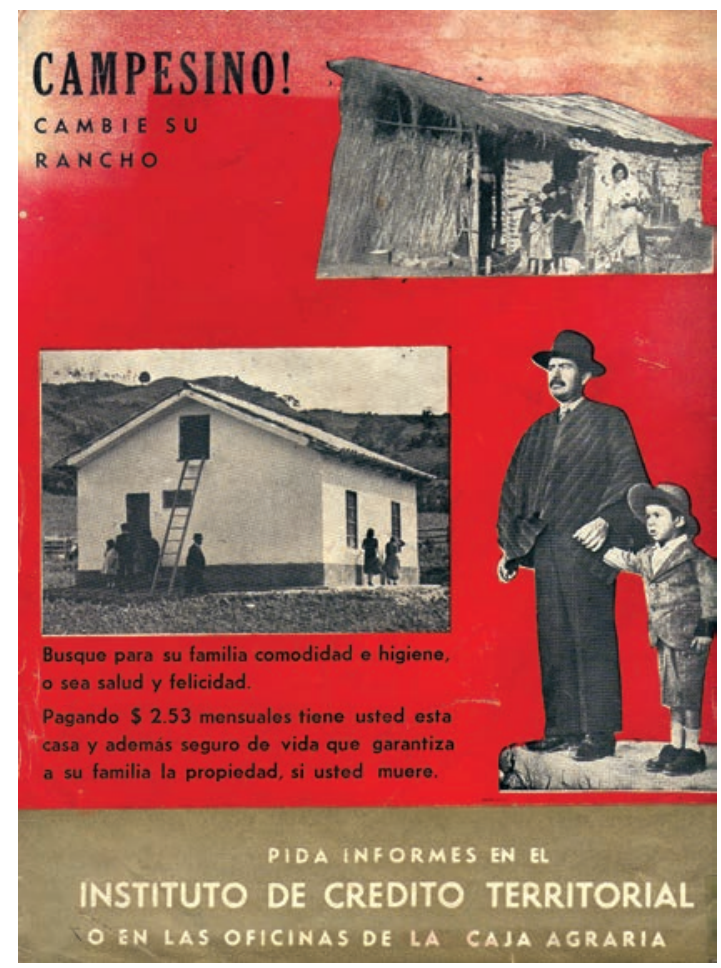

Fuente: ICT - Instituto de Crédito Territorial. Cartilla N ${ }^{\circ}$ I, mayo de 1940.

Aún queda una amplia labor por establecer las relaciones, a partir de la primera mitad del siglo XX, entre los devenires particulares de las tecnologías del saber, las tecnologías del control social y la consolidación de una cultura específica de los oficios afines a la arquitectura y la construcción. De la misma manera, sigue siendo válida la indagación por la respuestas de la tradición constructiva y de los procesos creativos de la Arquitectura ante los nuevos embates de los medios de producción, los medios de divulgación del saber y la transmisión tecnológica en esta tensión Centro-periferias. 


\section{BIBLIOGRAFÍA}

\section{Bibliografía principal}

Carpo, Mario. La Arquitectura en la Era de la Imprenta. Cátedra, Madrid, 2003 (I ${ }^{\mathrm{a}}$ ed. inglesa, 200I).

Evans, Robin. Traducciones. Pre-Textos de Arquitectura, COAC, Girona, 2005 (I ${ }^{\text {a }}$ ed. Inglesa, 1997).

Foucault, Michel. Vigilar y Castigar. Nacimiento de la prisión. Siglo XXI, Madrid, $13^{\mathrm{a}}$ reimpresión, 2005 ( ${ }^{\mathrm{a}}$ ed. francesa 1975).

GOMBRICH, Ernst. Los usos de las imágenes. Estudios sobre la función social del arte y la comunicación visual. Debate, Barcelona, I ${ }^{\mathrm{a}}$ ed. española 2003 ( I $^{\mathrm{a}}$ ed. inglesa 1999).

MARTíN-BARBERO, Jesús. De los medios a las mediaciones. Comunicación, cultura y hegemonía. Gili, México, 4ª ed. 1997 (Iª ed. Barcelona, I987). ISBN 968-887-024-2.

TUFTE, Edward R.Visual Explanations. Images and Quantities, Evidence and Narrative. Graphic Press LLC, Connecticut, 2005, 7ª. Ed. (I ${ }^{a}$. Ed. 1997). ISBN 0-96|392 I-4-2.

\section{Bibliografía complementaria}

AUGÉ, Marc. Los no lugares. Espacios del Anonimato. Gedisa, Barcelona, 9a. reimp. esp., 2005 ( $I^{\text {a }}$. ed. francesa, 1992).

BAUDRILLARD, Jean. El sistema de los objetos. Siglo XXI, México, $17^{\mathrm{a}}$ ed. esp. ( ${ }^{\mathrm{a}}$ ed. francesa, 1968).

BLOM, Philipp. Encyclopédie. El triunfo de la razón en tiempos irracionales. Anagrama, Barcelona, 2007 (I $I^{\text {a }}$ ed. Inglesa, 2004).

DEBRAY, Regis. Transmitir. Ediciones Manantial SRL, Buenos Aires, 1997 (I ${ }^{\mathrm{a}}$ ed. francesa 1997). ISBN 987-500-16-7.

GELERNTER, Mark. Sources of Architectural Form. A Critical History of Western Design Theory. Manchester University Press, Manchester, 1995. ISBN 0-7190-4I 29-5.

GIEDION, Siegfried. La mecanización toma el mando. Gili, Barcelona, 1978 ( I $^{\mathrm{a}}$ ed. inglesa, 1948). ISBN 84-252-0720-7.

GOMBRICH, Ernst. Instrucciones gráficas, en: BARLOW, Horace et al. Imagen y Conocimiento. Grijalbo, Barcelona, 1994. pp. I47-168.

HALLETT, Mark \& RIDING, Christine. Hogarth. Fundación "la Caixa”, Barcelona, 2007. ISBN 978-84-7664-940-4.

KRUFT, Hanno-Walter. Historia de la Teoría de la Arquitectura, Vols. I y 2. Alianza, Madrid, 1990.

PAl, Hyungmin. The Portfolio and the Diagram. Architecture, Discourse, and Modernity in America. MIT Press, Cambridge, 2002. ISBN 0-262-16206-7. 
PÉREZ-GÓMEZ, Alberto. Architecture and the Crisis of the Modern Science. MIT Press, Cambridge, $3^{\mathrm{a}}$ ed. 1985 (I ${ }^{\mathrm{a}}$ ed. 1983). ISBN 0-262-I609I-9.

PÉREZ-GÓMEZ, Alberto \& PELLETIER, Louise. Architectural Representation and the Perspective Hinge. MIT Press, Cambridge, 2000 (I la ed. 1997). ISBN 0-262-66 I I 3-6.

PÉREZ-GÓMEZ, Alberto. La Génesis y Superación del Funcionalismo en Arquitectura. Limusa, México, 1980. ISBN 968-18-II95-X.

ROBBINS, Edward. Why Architects Draw. MIT Press, Cambridge, 1997 (I ${ }^{\mathrm{a}}$ ed. 1994). ISBN $0-262-68098-X$.

SENNETT, Richard. La corrosión del carácter. Las consecuencias personales del trabajo en el nuevo capitalismo. Anagrama, Barcelona, $7^{\text {a }}$ ed. 2004 [ [ ${ }^{\mathrm{a}}$,edición, 2000]. ISBN 84-3390590-2.

SHESGREEN, Sean. Engravings by Hogarth. Dover Publications, New York, 1973. ISBN 0-486-22479-I.

TUFTE, Edward R. Envisioning Information. Graphic Press LLC, Connecticut, 2003, $9^{\mathrm{a}}$. ed. (I ${ }^{\text {a }}$ ed. I990). ISBN 0-96I392I-4-2.

TUFTE, Edward R. The Visual Display of Quantitative Information. Graphic Press LLC, Connecticut, 2006, 2a . ed. (I ${ }^{\mathrm{a}}$. ed. 200 I). ISBN 0-96I392I-4-2.

TWYMAN, Michael. The British Library Guide to Printing. History and Techniques. The British Library, London, 1998. ISBN 0-7/23-4588-4.

VESELY, Dalibor. Architecture in the Age of Divided Representation. The Question of Creativity in the Shadow of Production. MIT Press, Cambridge, 2004. ISBN 0-262-22067-9.

\section{Material documental consultado}

\section{Literaturas técnicas de los oficios constructivos}

ANDREANI, Isidoro. II Progettista Moderno di Costruzioni Architettoniche. Ulrico Hoepli, Milano, 1925. Quinta edición revisada y ampliada.

BENAVENT de BARBERÁ, Pere. Cómo debo construir. Manual práctico de construcción de edificios. Bosch, Barcelona, 1939, $2^{\text {a }}$ ed. castellana? (I a ed. catalana, 1934). 352 pp.

CASALI, I. Tipi Originali di Casette Popolari, Villini Economici ed Abitazioni Rurali. Ulrico Hoepli, Milán, 1928. Séptima edición ampliada.

CERUTTI, Atilio. Fognatura Domestica. Ulrico Hoepli, Milán, 1900. 421 pp., 200 ilustraciones.

CLAUDEL, J. \& LAROQUE, L. Enciclopedia Práctica de Construcción Moderna. Obra necesaria á los ingenieros, arquitectos, maestros de obras, etc.

Tomos V \& VI. Trabajos de albañilería. 
Tomo VII. Construcción de edificios (primera parte).

$7^{a}$ edición castellana, Ing. Geroges Dariés (dir.). Araluce, Barcelona, s.f.

CLAUDEL, J. \& LAROQUE, L. PRATIQUE DE L'ART DE CONSTRUIRE.- Maçonnerie, terrasse et platrerie. Quatrième edition, revue et considèrablement augmentée. Paris, Dunod, 1870.

DORRIES, F. El Ayudante Práctico en Albañilería. Editorial Cosmopolita, Buenos Aires, 1945.

DUCLOUT, Jorge A. VIVIENDAS RURALES ECONÓMICAS Para el estudio de las viviendas "fin de semana", suburbanas y rurales. Manuales de Información Técnica Rural. Tomo IV. Editorial Jorge A. Doclout, Buenos Aires, 1948. Tercera edición ampliada

FUENTES, Martín. Construcciones rurales. Pequeña Enciclopedia Práctica. Miñón S.A., Valladolid, s.f., $6 \mathrm{I}$ pp. [18.5 × $12 \mathrm{~cm}$, b/n, rústica]

GRAHAM, Frank D. (Dir.). AUDELS CARPENTERS AND BUILDERS GUIDE. A practical illustrated trade assistant for carpenters - joiners - builders - mechanics and all wood workers. 4 vol.Theo. Audel \& Co., New York, 1923

GRAHAM, Frank D. (Dir.). AUDELS MASONS AND BUILDERS GUIDE. A practical illustrated trade assistant for bricklayers - stone masons - cement workers - plasterers and tile setters. 4 vol. Theo. Audel \& Co., New York, 1924

MOIA, Jose Luis. Proyectos de Viviendas. Ediciones Windsor, Buenos Aires, 1953

REBOLLEDO, José A. Manual del Constructor. Librería Internacional de Romo, Madrid, 1926. $6^{\mathrm{a}}$ ed., $579 \mathrm{pp}$.

RESTREPO ALVAREZ, Gonzalo. Arquitectura Aldeana y Rural. Biblioteca Aldeana de Colombia. Imprenta Nacional, Bogotá, 1935

\section{Manuales de dibujo para arquitectura y artes aplicadas}

F.T.D. Perspectiva . Tratado práctico. Gili, Barcelona, 1947. $5^{a}$ ed., 223 pp. [23.6 x 15.4 $\mathrm{cm}$.

GIRÓ Y ARANOLS, Andrés. Curso metódico de dibujo lineal con aplicaciones a las artes, a la industria y a la agrimensura. Antonio ]. Bastinos, Barcelona, I901. $9^{a}$ ed., 320 pp. [18.6 $x \mid 1.5 \mathrm{~cm}]$

SALO, A. [Saló i Marco, Antoni?]. Prácticas de Dibujo para las Artes Decorativas. Dibujo, perspectiva, estilos. Feliu y Susana, Barcelona, s.f. (ca. 1935), 362 pp. [2I.8 x $14.5 \mathrm{~cm}$.] 


\section{Publicaciones de índole académica}

CHOISY, Auguste. Historia de la Arquitectura, vol. I. Editorial Victor Leru, Buenos Aires, 1944. I I edición completa en español ( ${ }^{\mathrm{a}}$ ed. francesa, I896).

DURAND, Jean Nicholas Louis. Precis des Leçons d'Architecture. Partie graphique des cours d'Architecture. Firmin Didot, Paris, 1802-1805.

HEGEMANN, Werner. Amerikanische Architektur \& Stadtbaukunst (ein überblick ubre den heutigen stand der amerikanischen baukunst in-ihrer beziehung zum staedtebau). Ernst Wasmuth A.G., Berlin, 1925.

McGRATH, Raymond.Twentieth-Century Houses. Faber \& Faber, The University Press Cambridge, London, 1934.

MUTTESIUS, Hermann. The English House. Rizzoli, Nueva York, I987. ISBN 0-84780826-2(pbk), (I ${ }^{\text {a }}$ Ed. Alemana I904- 1905).

NEUFERT, Ernst. Arte de Proyectar en Arquitectura. Fundamentos, Normas y Prescripciones sobre Construcción, Instalaciones, Distribución y Programas de necesidades. Dimensiones de edificios, locales y utensilios. (Consultor para arquitectos, ingenieros, aparejadores, constructores, propietarios y estudiantes).

Gili, Buenos Aires, 1944. $2^{\mathrm{a}}$ edición castellana ( $8^{\mathrm{a}}$ alemana). 285 pp., 3600 ilustr

Gili, Barcelona, 1945, $2^{\mathrm{a}}$ edición castellana ( $10^{\mathrm{a}}$ alemana), 285 pp., 3600 ilustr.

Gili, Barcelona, 1948?, s.f., sin número de edición., 285 pp., 3600 ilustr.

Gili, Barcelona, 1970, $12^{\mathrm{a}}$ ed. castellana, $2^{\mathrm{a}}$ tirada (26 alemana), 447 pp., 5000 ilustr.

Gili, Barcelona, 2006, $15^{\text {a }}$ ed. castellana, 672 pp., 6900 ilus. y tablas.

Revista INGENIERÍA Y ARQUITECTURA (varios ejemplares consultados).

Facultades de Ingeniería y Arquitectura, Universidad Nacional de Colombia, Bogotá, desde 1939 hasta 1968.

SCHAEFER, Karl

La arquitectura de occidente. (Trad. José Camón Aznar). Labor S.A., Barcelona, 1929. 360 pp. $[18 \times 12.1 \mathrm{~cm}]$ 


\section{Publicaciones de decoración y complementos domésticos}

KIMBALL, Fiske. The House Beatiful Furnishing Annual. The Atlantic Monthly Company, Boston, 1926. 168 pp. [ $32 \times 24 \mathrm{~cm}$.]

Revista Neuzeitliche Raumkunst. STAFFA, Siegfried (ed.). S.E., Viena, s.f. [2I x $30.5 \mathrm{~cm}$, b/n, rústica] Ejemplares consultados: I4, 15 \& 16.

S.A. Arts, Construcció, Decoració. L’Abella d'Or, Barcelona, 1932. 252 pp. (s.n.), [22 x $1 \mathrm{l} .4 \mathrm{~cm}, \mathrm{~b} / \mathrm{n}$, rústica]

S.A. Home Furnishing and Decoration. Including furniture-making for the amateur. Household Reference Library. The Amalgamated Press, London, s.f., 640 pp.

WISEMAN, E.J. Victorian Do-It-Yourself. Handicrafts and Pastimes of the 1880s. New Abbot, London, 1976. ISBN 0-7I53-7307-2.

\section{Publicaciones de hobbies}

GOLDSMITH, Milton. Practical Things With Simple Tools. A Book for Young Mechanics. George Sully and Company, New York, 1916.

NATKIN, Marcel. El arte de obtener buenas fotografías. Iberia S.A., Barcelona, 1936 (3a ed.), 174 pp., [19.3 x $13.5 \mathrm{~cm}$.).

Revista MARILU (varios ejemplares consultados). Editorial Atlántida, Buenos Aires, desde 1933.

S.A. Cutting and Fitting. Cutting, foundations for fitting. Fitting, the dress form. The Woman's Institute of Domestic Arts and Sciences, Scranton, Pa., 1928

S.A. El muchacho moderno. El libro de los grandes inventos. Editorial Juventud, Barcelona, 1937, $2^{\mathrm{a}}$ ed. (I ${ }^{\mathrm{a}}$ ed. 1935). 174 pp.

S.A. Picture taking wiht the N ${ }^{\circ} .0$ Brownie Camera. Eastman Kodak Company, Rochester, N.Y., s.f. (ca. 1925).

\section{Publicaciones de urbanidad, higiene y salud}

BURGENSTEIN, Leo. Higiene Escolar. (Trad. Jaumandreu, Eugenio \& Antonio; Sánchez Sarto, Luis). Labor, Barcelona, 1937, 3 ${ }^{\mathrm{a}}$ ed. (I ${ }^{\mathrm{a}}$ ed. 1929). 235 pp. [18.5 x I3 cm].

F.T.D. Cartilla moderna de urbanidad (niñas). F.T.D., Barcelona, 1929 (3ª ed.). 64 pp. [16.2 $x \mid 1.7 \mathrm{~cm}]$. 
F.T.D. Cartilla moderna de urbanidad (niños). F.T.D., Barcelona, 1928 (2 $2^{\mathrm{a}}$ ed.). 64 pp. [16.2 $x 11.7 \mathrm{~cm}]$.

OPISSO, Alfredo. Medicina Doméstica. Guía para los primeros auxilios en casos de enfermedades apremiantes y en los accidentes desgraciados. Manuales Gallach (antes Manuales Soler) \# 44. José Gallach, Barcelona, s.f., 310 pp. [15.5 x $10.5 \mathrm{~cm}$, b/n, pasta dura].

Pío X, Papa. Catecismo de la Doctrina Cristiana, según el texto de S.S. el Beato Pio X, Papa.. Segundo Grado (Catecismo Breve). La Hormiga de Oro S.A., Barcelona, 1934. 64 pp. [14.6 × $9.5 \mathrm{~cm}, \mathrm{~b} / \mathrm{n}$, rústica].

Revista Salud y Sanidad. Mejor es prevenir que curar (varios ejemplares consultados). Departamento Nacional de Higiene (Sección de Sanidad Rural) para la vulgarización de la Higiene pública y privada. Bogotá, Colombia. (números continuos consultados entre el 25 de 1934 y el 75 de 1938). [23.30 x $16.7 \mathrm{~cm}, \mathrm{~b} / \mathrm{n}+$ color, rústica]. 


\section{FE DE ERRATAS}

La Revista M presenta excusas a la arquitecta Amaya Martínez Marcos, autora del artículo "Colegios paradigmáticos de la Arquitectura Moderna Valenciana" por los errores cometidos en el Volumen 5, No. 2 correspondiente al período Julio-Diciembre de 2008, el primero de ellos relacionado con la alteración de su nombre en la bandera y tabla de contenido de la revista; el segundo por la no correspondencia de algunas imágenes con su respectivo pie de fotos. A continuación se publica el listado de las imágenes, textos y créditos correspondientes a cada una de ellas:

\section{RESUMEN}

A. Colegio Pureza de María. Foto: Xaume Olleros, 2007.

B. Colegio Guadalaviar. Foto: Amaya Martínez, 2007.

\section{INTRODUCCIÓN}

I. Colegio Guadalaviar. Detalle del rótulo. Foto: Amaya Martínez, 2007.

2. Colegio Alemán. Detalle del rótulo. Foto: Xaume Olleros, 2007.

3. Colegio Pureza de María. Detalle del rótulo. Foto: Xaume Olleros, 2007.

\section{APROXIMACIÓN A LA ARQUITECTURA MODERNA VALENCIANA}

4. Escuelas Graduadas en Rocafort (1932) de A. Baeschlin.

Foto: Registro de Arquitectura del Siglo XX. C.V. 2002.

5. Colegio Jesús y María (1952) de A. Borell Sensat.

Foto: Registro de Arquitectura del siglo XX. C.V. 2002.

6. Facultad de Derecho en Valencia (1959) de F. Moreno Barberá.

Foto: Registro de Arquitectura del Siglo XX. C.V. 2002.

7. Grupo Escolar Primer Marqués del Turia en Valencia (1957-60) de R. Fernández Huidobro y P. Pintado Riba.

Foto: Amaya Martínez, 2007.

8. Escuelas Profesionales San José en Valencia (1962) de Borso di Carminati González y R. Contel Comenge. Foto: Amaya Martínez, 2007.

\section{7-1960. COLEGIO GUADALAVIAR}

9. Colegio Guadalaviar desde la Av. Blasco lbáñez. Foto: Amaya Martínez, 2007.

10. Colegio Guadalaviar. Imagen aérea. Foto: Google Earth, 2007.

\section{8-196I. COLEGIO ALEMÁN}

II. Colegio Alemán desde la Calle Jaime Roig. Foto: Xaume Olleros, 2007.

12. Colegio Alemán. Imagen aérea. Foto: Google Earth, 2007.

\section{2-1965. COLEGIO PUREZA DE MARÍA}

13. 1962-63. Colegio Pureza de María desde la Av. del Cid. Foto: Xaume Olleros, 2007. 14. 1962-63. Colegio Pureza de María. Imagen aérea. Foto: Google Earth, 2007.

\section{ANÁLISIS COMPARATIVO}

IMPLANTACIÓN EN EL SOLAR. ORGANIZACIÓN DE LOS VOLÚMENES.

Figura I. Colegio Guadalaviar. Implantación. Redibujo: Amaya Martínez, 2007.

Figura 2. Colegio Alemán. Implantación. Redibujo: Amaya Martínez, 2007.

Figura 3. Colegio Pureza de María. Implantación. Redibujo: Amaya Martínez, 2007.

CONFIGURACIÓN DEL ACCESO. DISEÑO DE LOS ESPACIOS EXTERIORES.

15. Colegio Guadalaviar. Acceso desde la Av. de Aragón. Foto: Amaya Martínez, 2007.

16. Colegio Alemán. Acceso desde la calle Jaime Roig. Foto: Xaume Olleros, 2007.

17. Colegio Guadalaviar. Jardines interiores. Foto: L'Architecture d'Aujourd'hui, nº94, 1961. 
18. Colegio Alemán. Patio de juegos interior. Foto: Archivo personal P. Navarro Alvargónzalez, 1963.

19. Colegio Pureza de María. Jardín interior y zona de juegos. Foto: Xaume Olleros, 2007.

20. Colegio Pureza de María. Acceso desde la Av. del Cid. Foto: Xaume Olleros, 2007.

\section{CRITERIOS ESTRUCTURALES Y PLANTA TIPO.}

Figura 4. Colegio Guadalaviar. Planta tipo y modulación estructural. Redibujo: Amaya Martínez, 2007.

Figura 5. Colegio Pureza de María. Planta tipo y modulación estructural. Redibujo: Amaya Martínez, 2007.

Figura 6. Colegio Alemán. Planta tipo y modulación estructural. Redibujo: Amaya Martínez, 2007.

\section{FACHADAS: COMPOSICIÓN, MATERIALIDAD Y RELACIÓN INTERIOR- EXTERIOR.}

21. Colegio Guadalaviar. Fachadas Sur y Este. Foto: L’Architecture d'Aujourd'hui, n94, 1961.

22. Colegio Alemán. Fachada de los corredores a Oeste. Foto: Xaume Olleros, 2007.

23. Colegio Guadalaviar. Fachada de las aulas a Sur. Foto: L'Architecture d'Aujourd'hui, $\mathrm{n}^{\circ} 94,1961$.

24. Colegio Alemán. Fachada de las aulas a Este. Foto: Xaume Olleros, 2007.

25. Colegio Pureza de María. Fachada de las aulas a Sur. Foto: Xaume Olleros, 2007.

26. Colegio Pureza de María. Fachada de las aulas especiales a Este. Foto: Amaya Martínez, 2007.

\section{LOS PABELLONES DE INFANTIL}

Figura 7. Colegio Guadalaviar. Pabellones de infantil, planta del conjunto, alzados y aula tipo. Redibujo: Amaya Martínez, 2007.

Figura 8. Colegio Pureza de María. Pabellones de infantil: planta del conjunto, alzado Oeste y aula tipo. Redibujo: Amaya Martínez, 2007.

Figura 9. Colegio Alemán. Pabellones de infantil: planta del conjunto, alzado Oeste y aula tipo. Redibujo: Amaya Martínez, 2007.

27. Colegio Guadalaviar. Pabellones de infantil: alzado sur imagen de época. Foto: Informes de la Construcción n일, 1960.

28. Colegio Alemán. Pabellones de infantil: alzado oeste desde el patio de juegos. Foto: Archivo personal P. Navarro Alvargnzález, 1963

29. Colegio Pureza de María. Pabellones de infantil: alzado sureste. Foto: Xaume Olleros, 2007.

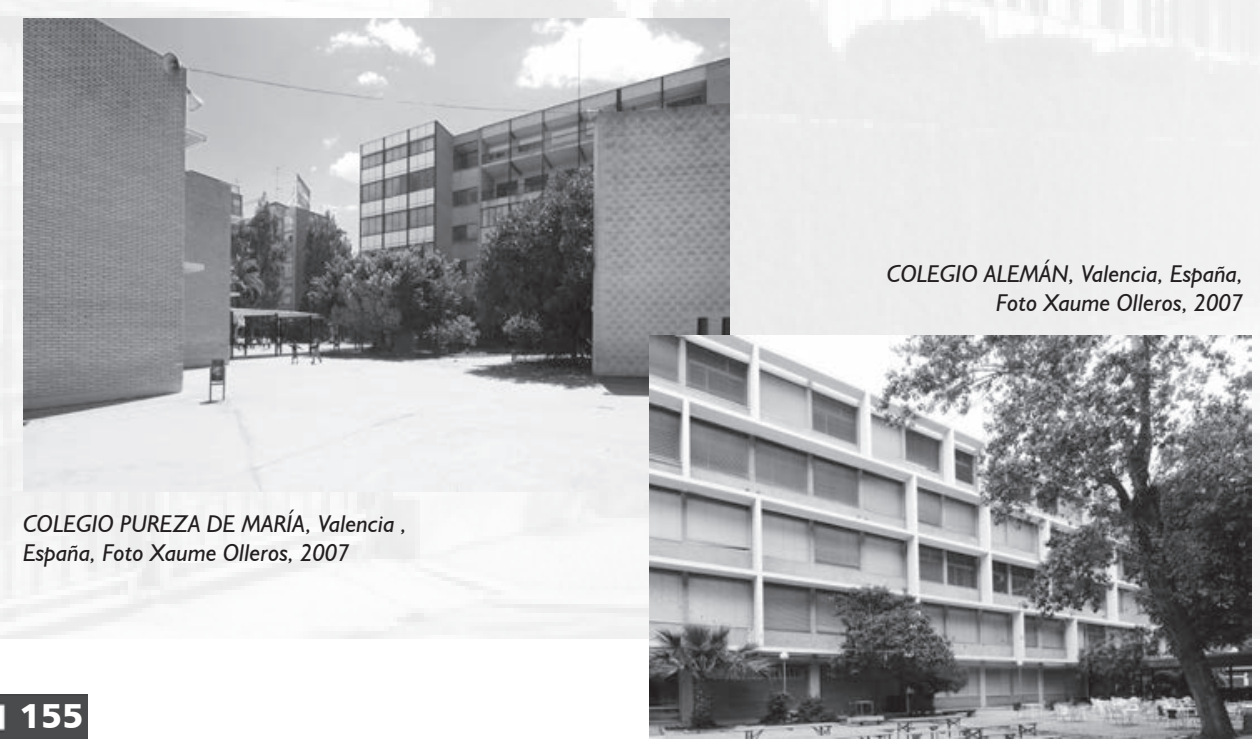

